\title{
Impact of the Antarctic Ozone Hole on the Vertical Coupling of the Stratosphere-Mesosphere-Lower Thermosphere System ${ }^{\circ}$
}

\author{
SANDRO W. LUBIS \\ GEOMAR Helmholtz Centre for Ocean Research Kiel, Kiel, Germany \\ NOUR-EDDINE OMRANI \\ Geophysical Institute, University of Bergen, and Bjerknes Centre for Climate Research, Bergen, Norway, \\ and GEOMAR Helmholtz Centre for Ocean Research Kiel, Kiel, Germany \\ KATJA MATTHES \\ GEOMAR Helmholtz Centre for Ocean Research Kiel, and Christian-Albrechts \\ Universität zu Kiel, Kiel, Germany \\ SEBASTIAN WAHL \\ GEOMAR Helmholtz Centre for Ocean Research Kiel, Kiel, Germany
}

(Manuscript received 9 July 2015, in final form 9 March 2016)

\begin{abstract}
There is evidence that the strengthened stratospheric westerlies arising from the Antarctic ozone holeinduced cooling cause a polar mesospheric warming and a subsequent cooling in the lower thermosphere. While previous studies focus on the role of nonresolved (gravity) wave drag filtering, here the role of resolved (planetary) wave drag and radiative forcing on the Antarctic mesosphere and lower thermosphere (MLT) is explored in detail. Using simulations with NCAR's Community Earth System Model, version 1 (Whole Atmosphere Community Climate Model) [CESM1(WACCM)], it is found that in late spring and early summer the anomalous polar mesospheric warming induced by easterly nonresolved wave drag is dampened by anomalous dynamical cooling induced by westerly resolved wave drag. This resolved wave drag is attributed to planetary-scale wave $(k=1-3)$ activity, which is generated in situ as a result of increased instability of the summer mesospheric easterly jet induced by the ozone hole. On the other hand, the anomalous cooling in the polar lower thermosphere induced by westerly nonresolved wave drag is enhanced by anomalous dynamical cooling due to westerly resolved wave drag. In addition, radiative effects from increased greenhouse gases during the ozone hole period contribute partially to the cooling in the polar lower thermosphere.

The polar MLT temperature response to the Antarctic ozone hole is, through thermal wind balance, accompanied by the downward migration of anomalous zonal-mean wind from the lower thermosphere to the stratopause. The results highlight that a proper accounting of both dynamical and radiative effects is required in order to correctly attribute the causes of the polar MLT response to the Antarctic ozone hole.
\end{abstract}

Supplemental information related to this paper is available at the Journals Online website: http://dx.doi.org/10.1175/ JAS-D-15-0189.s1.

Corresponding author address: Sandro W. Lubis, GEOMAR Helmholtz Centre for Ocean Research Kiel, Düsternbrooker Weg. 20, 24105 Kiel, Germany.

E-mail: slubis@geomar.de

\section{Introduction}

Ever since the first observation of the Antarctic ozone hole in the mid-1980s, the cause of springtime ozone loss and its impacts on the atmospheric circulation and surface climate has been investigated in great detail (e.g., Thompson and Solomon 2002; Gillett and Thompson 2003; Pawson et al. 2008; Son et al. 2010; Eyring et al. 2010, chapters 4-8; Polvani et al. 2011; Orr et al. 2012, 
2013; WMO 2014). This springtime ozone loss is mainly caused by increased anthropogenic emissions of chlorofluorocarbons (CFC) and other halogenated species containing bromine and chlorine (Solomon et al. 1986; Molina and Molina 1987; WMO 2014). In particular, when there is not enough sunlight in the polar winter stratosphere to initiate photochemistry, the conversion of reservoir chlorine molecules into chlorine gas takes place on the surface of polar stratospheric clouds (PSCs) (e.g., Solomon et al. 1986). In the spring, when the polar stratosphere becomes sunlit, solar ultraviolet (UV) radiation splits the chlorine gas molecules into radical chlorine atoms and makes them much more effective at destroying ozone through catalytic cycles (e.g., Molina and Molina 1987).

One striking effect of the stratospheric ozone loss is the radiative cooling associated with a reduction of absorbed solar UV radiation. This effect is evident in observations as indicated by negative trends of polar lower-stratospheric temperatures during spring and early summer (e.g., Thompson and Solomon 2002; Randel et al. 2009). Through thermal wind balance, the resulting increased meridional temperature gradient must be accompanied by increased vertical shear of the geostrophic wind, leading to a strengthening of the polar vortex (e.g., Waugh et al. 1999; Thompson and Solomon 2002; Orr et al. 2012). In the troposphere, this anomalous circulation change resembles the patterns projecting onto the positive phase of the southern annular mode (SAM) [see Son et al. (2010) for an overview of possible mechanisms], which is often described as the poleward shift in the tropospheric jet and extratropical storm track (e.g., Simmonds and Keay 2000; Wang et al. 2013). Changes in SAM trends during the ozone hole period have had a significant impact on the Southern Hemisphere (SH) regional surface climate (e.g., Thompson and Solomon 2002; Ummenhofer et al. 2009).

Changes in the SH stratosphere due to the ozone hole can also affect the mesosphere and lower thermosphere (MLT). The primary mechanism is changes in the propagation of gravity waves (GWs) due to the change in background stratospheric winds (Smith et al. 2010; Smith 2012). Smith et al. (2010), using simulations with the Whole Atmosphere Community Climate Model (WACCM), show that ozone-loss-induced changes in the stratospheric wind lead to a warming of the polar summer mesopause. This is attributed to a weakening of the westerly gravity wave drag (GWD) in the mesosphere during late spring and early summer (NovemberDecember). In particular, strengthened westerly winds in the stratosphere enhance filtering of westerly GWD as they approach critical levels (i.e., the phase speed of GWs becomes equal to the background wind speed).
This results in increased easterly GWD in the mesosphere, leading to a weakening of the polar summer upwelling and the associated adiabatic warming in this region. However, the role of resolved planetary wave drag on the MLT temperature and circulation responses to the Antarctic ozone hole remains unclear.

More recently, Lossow et al. (2012), using simulations with the Canadian Middle Atmosphere Model (CMAM), show that $\mathrm{SH}$ mesospheric responses to the stratospheric ozone loss differ significantly between late spring and early summer. In late spring, the strengthened lowerstratospheric westerlies increase filtering of the westerly GWD, resulting in more anomalous easterly GWD in the mesosphere. This leads to anomalous polar downwelling and associated anomalous warming in the polar summer mesosphere, similar to Smith et al. (2010). In early summer, however, the strengthened mesospheric easterlies due to increased easterly GWD, induce a westerly resolved planetary wave drag anomaly through baroclinic instability. The resulting polar mesospheric cooling induced by this process dominates the uppermesospheric temperature responses to the ozone hole in early summer. The latter result is in contrast to the Smith et al. (2010) findings, which do not show a significant difference in the mesospheric temperature responses between late spring and early summer. These differing results could be associated with a delayed breakdown of the SH vortex in WACCM, which is approximately a few weeks later than it occurs in CMAM (Lossow et al. 2012). Consequently, the mesospheric warming induced by the ozone hole in WACCM persists longer into early summer. Nevertheless, the structures of the changes that occur in dynamical variables are very similar between WACCM and CMAM. Despite these results, it is still not clear how large the radiative effects from increased ozone-depleting substances (ODSs) and greenhouse gases (GHGs) are and how they influence the MLT temperature and circulation responses during the Antarctic ozone hole period. We attempt to address this question with this study.

It is well established that planetary waves contribute to the circulation and the large dynamical variability in the MLT (Becker 2012; Smith 2012). Although most of these waves are generated in the troposphere, they can be also forced in situ in the mesosphere via instability of the zonal-mean state (Garcia et al. 2005; Becker 2012; Smith 2012). Two examples are in situ generation of the quasi-2-day wave (QTDW) and 5-day planetary wave $(k=1)$ via baroclinic instability of the easterly jet in the summer mesosphere (Plumb 1983; Pfister 1985; Norton and Thuburn 1999; Garcia et al. 2005). The strengthening of the mesospheric easterlies induced by the ozone hole could affect the susceptibility of the mesosphere to 
be more baroclinically or barotropically unstable and hence increase the probability of in situ planetary wave generation. Lossow et al. (2012) finds that there is a pronounced increase of the resolved wave drag in the summer upper mesosphere due to the Antarctic ozone hole. However, their calculations show that such changes are mainly attributed to synoptic-scale waves rather than planetary-scale waves like QTDW $(k=3)$ or 5 -day waves $(k=1)$. As discussed in Lossow et al. (2012), there are at least two potential issues that might affect the resolved wave drag response in their simulations: 1) the use of the Scinocca (2003) nonorographic GWD parameterization in CMAM tends to dampen the amplitude of the QTDW (McLandress and Scinocca 2005) and 2) the response of the resolved planetary wave drag in the upper mesosphere was possibly affected by the location of the model lid $(\sim 95 \mathrm{~km})$, as indicated by the large negative PV gradient maximizing close to this location $\sim 90 \mathrm{~km}$ [see Lossow et al. (2012) for a detailed explanation]. Therefore, further investigations with a higher-lid model are needed to address this possibility.

A prominent feature of mesospheric dynamics is the interhemispheric circulation from summer to winter pole (Murgatroyd and Singleton 1961; Plumb 2002; Butchart 2014). This circulation is driven primarily by upwardpropagating GWs, with their effect on the mesospheric mean flow depending on their phase velocities and the background wind patterns (Holton 1983; Plumb 2002). In the summer (winter) hemisphere, an equatorward (a poleward) residual circulation in the mesosphere is induced by westerly (easterly) GWD, resulting from filtering of easterly (westerly) GWD by stratospheric background winds. In contrast to the mesosphere, the winter stratosphere is dominated by a poleward residual circulation from the tropics to the pole (Plumb 2002; Butchart 2014). This circulation arises primarily from the dissipation of upward-propagating planetary-scale Rossby waves in the stratosphere. In the upper troposphere and lower stratosphere, the poleward flow of the residual circulation is driven mainly by synoptic-scale wave activity, which persists throughout the year (Plumb 2002).

The radiatively or wave-induced strengthening of the polar vortex can suppress the upward wave propagation from the troposphere into the stratosphere (Charney and Drazin 1961), which results in further strengthening of the polar vortex. This positive feedback can be strengthened by the buoyancy frequency and the westerly winds near the tropopause (Chen and Robinson 1992), which lead to additional reduction of the upwardpropagating wave and, thus, inducing downward propagation of the wind anomalies toward the tropopause (e.g., Kuroda and Kodera 1998). Orr et al. (2012) show that this positive feedback mechanism explains the downward migration of zonal-mean wind anomalies toward the tropopause during the Antarctic ozone hole period. For the ozone-induced tropospheric changes, there is recent evidence that the internal tropospheric eddy-driven dynamics play crucial role for shaping and maintaining the tropospheric response to the ozone hole (Ogawa et al. 2015). Given the fact that stratospheretroposphere coupling associated with the ozone hole has been widely investigated, our study will focus on the mechanisms maintaining the vertical coupling in the middle atmosphere from the stratosphere toward the mesosphere and lower thermosphere.

In this paper, we perform experiments with the NCAR's Community Earth System Model, version 1 (Whole Atmosphere Community Climate Model) [CESM1(WACCM)], a state-of-the-art fully coupled chemistry-climate model, to further investigate the impact of the Antarctic ozone hole on the vertical coupling of the stratosphere-MLT system. While previous studies focused on the impact of nonresolved (gravity) wave drag filtering, this study investigates in detail the role of both resolved (planetary) wave drag and radiative forcing (short- and longwave radiation) during the Antarctic ozone hole period in the model. We address the following questions:

1) What are the roles of resolved wave drag and radiative forcing on the MLT temperature responses to the Antarctic ozone hole?

2) What are the dynamical mechanisms responsible for maintaining the downward propagation of zonal wind anomalies in the MLT?

3) What is the dynamical origin of the pronounced change in the resolved wave drag responses in the MLT?

Section 2 describes the data and methods. The results are presented in sections 3-5. Finally, the paper finishes with a summary and discussion in section 6 .

\section{Model, simulations, and analysis}

\section{a. Model description}

We use version 1.0.2 of the NCAR's Community Earth System Model (CESM), a fully coupled general circulation model developed based on the Community Climate System Model version 4 (CCSM-4; Gent et al. 2011), which includes an interactive ocean, land, sea ice, and atmosphere (Marsh et al. 2013). For the simulations analyzed here, we use WACCM version 4 as the atmosphere component of CESM, which is the successor of WACCM version 3.5 used by Smith et al. (2010). WACCM uses the finite-volume dynamical core with a horizontal resolution of $1.9^{\circ}$ latitude by $2.5^{\circ}$ longitude 
TABLE 1. Description of CESM1(WACCM) transient and timeslice experiments. TR = transient run and TS = timeslice run. All experiments are run with interactive SSTs and sea ice.

\begin{tabular}{llll}
\hline \hline Experiment & \multicolumn{1}{c}{ Period } & \multicolumn{1}{c}{ GHGs } & ODSs \\
\hline CTL-TR & $1955-2099(145 \mathrm{yr})$ & $1960 \mathrm{~s}$ level & $1960 \mathrm{~s}$ level \\
GHGODS-TR & $1955-2099(145 \mathrm{yr})$ & OBS+RCP8.5 & OBS+RCP8.5 \\
ODS2010-TS & $40 \mathrm{yr}$ & $1960 \mathrm{~s}$ level & $2010 \mathrm{~s}$ level \\
GHG2010-TS & $40 \mathrm{yr}$ & $2010 \mathrm{~s}$ level & $1960 \mathrm{~s}$ level \\
REF-TS & $40 \mathrm{yr}$ & $2010 \mathrm{~s}$ level & $2010 \mathrm{~s}$ level \\
\hline
\end{tabular}

${ }^{a}$ GHG/ODS follows observations until 2005 and the RCP8.5 scenario thereafter.

and 66 vertical levels from the surface to the lower thermosphere at an altitude of $\sim 140 \mathrm{~km}(\sim 5.9 \times$ $\left.10^{-6} \mathrm{hPa}\right)$. Chemical processes in WACCM are represented by the 3D chemical transport Model of Ozone and Related Chemical Tracers, version 3 (MOZART-3; Kinnison et al. 2007). This includes the $\mathrm{O}_{x}, \mathrm{NO}_{x}, \mathrm{HO}_{x}$, $\mathrm{ClO}_{x}$, and $\mathrm{BrO}_{x}$ chemical families, along with $\mathrm{CH}_{4}$ species within the chemical and physical processes in the troposphere through the lower thermosphere (i.e., fully interactive and fully coupled chemistry and physics). WACCM is not able to resolve small-scale GWs with horizontal wavelengths of tens up to several hundred kilometers, and hence they need to be parameterized (Richter et al. 2010). Therefore, WACCM employs an updated parameterization of nonorographic GWs generated by frontal systems and convection and surface stress due to unresolved topography (Richter et al. 2010). Other processes important for the mesosphere and lower thermosphere such as ion chemistry, auroral processes, and extreme ultraviolet and nonlocal thermodynamic equilibrium radiation are also implemented [see Marsh et al. (2013) for specific details].

\section{b. Model simulations}

We perform five model experiments (summarized in Table 1) to study the impact of the Antarctic ozone hole on the vertical coupling of the stratosphere-MLT system. The first two transient (TR) experiments are CTLTR and GHGODS-TR, covering $145 \mathrm{yr}$ from 1955 to 2099. Both experiments use a nudged quasi-biennial oscillation (QBO) signal in zonal-mean winds between $22^{\circ} \mathrm{S}$ and $22^{\circ} \mathrm{N}$ following the approach by Matthes et al. (2010). The QBO is projected into the future by developing Fourier coefficients for the QBO time series based on climatological values of Giorgetta ${ }^{1}$ from the past records (1954-2004). The QBO nudging allows us to study the dynamical impact of the tropics on the extratropics and the high latitudes. The effects of QBO

\footnotetext{
${ }^{1}$ http://www.pa.op.dlr.de/CCMVal/Forcings/qbo_data_ccmval/ u_profile_195301-200412.html.
}

nudging in CESM1(WACCM) on extratropical and high latitude dynamics agrees well with observations (Hansen et al. 2013). The solar cycle was prescribed using spectrally resolved daily variations of solar incoming radiation at the top of the atmosphere following Lean et al. (2005) and was projected into the future by repeating cycles 20-23 from the years 1965 to 2008 . The CTL-TR experiment uses a perpetual annual cycle of all anthropogenic forcing including airplane emissions at pre-ozone hole conditions averaged from 1955 to 1965 , which we refer to as 1960 s conditions, and therefore no ozone hole develops in this simulation.

The GHGODS-TR experiment uses transient anthropogenic forcing following observations until 2005 and phase 5 of the Coupled Model Intercomparison Project (CMIP5) representative concentration pathways (RCP) scenario 8.5 (Taylor et al. 2012; Meinshausen et al. 2011) thereafter, and consequently an ozone hole develops, peaking in 2010. The RCP8.5 scenario includes future projections of surface emissions of both GHGs and ODSs as described in Meinshausen et al. (2011). Both model simulations are initialized using initial files for January 1955 from a CESM-piControl experiment ${ }^{2}$ from the CESM contribution to CMIP5, which runs for several hundred years to reach an equilibrium state in the ocean. Therefore, the differences between GHGODSTR and CTL-TR experiments can be used to study the relative effects of ODSs and GHGs during the period of the ozone hole or future ozone recovery (depending on the time periods used for the analysis).

To examine whether the responses obtained from the transient simulation during the Antarctic ozone hole period are attributed mainly to ozone depletion or due to the effects of GHGs, three 40-yr timeslice (TS) experiments with different combinations in prescribed surface emissions of the ODSs and GHGs are performed. The reference timeslice experiment (REF-TS) uses a perpetual annual cycle of surface emissions of

\footnotetext{
${ }^{2}$ http://www.cgd.ucar.edu/ccr/strandwg/CMIP5_experiment_list. html.
} 
both ODSs and GHGs averaged from 2005 to 2015, which represent emissions during the deep ozone hole condition (refer to as 2010 conditions). The GHG2010TS experiment uses seasonally varying surface emissions of ODSs at 1960s levels in combination with surface emissions of GHGs at 2010 levels. For the ODS2010-TS experiment, ODSs at 2010 levels in combination with surface emissions of GHGs at 1960s levels are used. All timeslice experiments are initialized using restart files from year 2010 of the GHGODS-TR run and are coupled with interactive ocean and sea ice. All other external forcings are kept constant at the 2010 levels. Therefore, the differences between the GHG2010-TS (ODS2010-TS) and REF-TS experiments reveal the effects of polar stratospheric ozone depletion (climate change due to increased GHGs).

\section{c. Analysis framework}

The transformed Eulerian mean (TEM) zonal momentum and thermodynamic budget analysis are used to study the vertical coupling associated with the ozone hole (Andrews et al. 1987; Orr et al. 2012, 2013; Keeble et al. 2014), as follows:

$$
\begin{aligned}
& {[u]_{t}+\zeta_{a}[v]^{\dagger}+[w]^{\dagger}[u]_{z}-[X]=\frac{1}{\rho_{0} a \cos \phi} \nabla \cdot \mathbf{F} \text { and }} \\
& {[\theta]_{t}+\frac{1}{a}[v]^{\dagger}[\theta]_{\phi}+[w]^{\dagger}[\theta]_{z}-\left[Q_{\mathrm{dia}}\right]} \\
& =-\frac{1}{\rho_{0}}\left\{\rho_{0}\left(\frac{\left[v^{*} \theta^{*}\right]\left[\theta_{\phi}\right]}{a[\theta]_{z}}+\left[w^{*} \theta^{*}\right]\right)\right\}_{z},
\end{aligned}
$$

where $\zeta_{a}=(a \cos \phi)^{-1}([u] \cos \phi)_{\phi}-f ;\left[Q_{\text {dia }}\right]$ is a total diabatic source; $u, v$, and $w$ are, respectively, the zonal, meridional, and vertical components of the velocity; $a$ is Earth's radius; $f$ is the Coriolis parameter; $\phi$ is latitude; $z$ is height (in log-pressure coordinates); $\rho_{0}$ is air density, which varies with height as $\exp (-z / H) ; H$ is the density-scale height taken as $7000 \mathrm{~m}$; and $\theta$ is potential temperature. The subscripts mean the derivative with respect to the corresponding coordinate. The asterisks are used for the total waves (deviation from the zonal mean in all frequencies) and square brackets for the zonal mean. The $[v]^{\dagger}$ and $[w]^{\dagger}$ in Eq. (1) denote the TEM residual meridional and vertical winds, which are defined as $[v]^{\dagger}=[v]-\rho_{0}^{-1}\left(\rho_{0}\left[v^{*} \theta^{*}\right] /[\theta]_{z}\right)_{z}$ and $[w]^{\dagger}=[w]+$ $(a \cos \phi)^{-1}\left(\cos \phi\left[v^{*} \theta^{*}\right] /[\theta]_{z}\right)_{\phi}$. The term $[X]$ represents the unresolved forcing that includes the nonresolved GWs, smaller-scale turbulent diffusion, friction, etc.

We use the term "resolved wave drag" as a synonym for the divergence of the Eliassen-Palm (EP) flux $\left(\rho_{0} a \cos \phi\right)^{-1} \nabla \cdot \mathbf{F}\left(F_{y}, F_{z}\right)$, associated with resolved planetary wave activity, where the components are given by

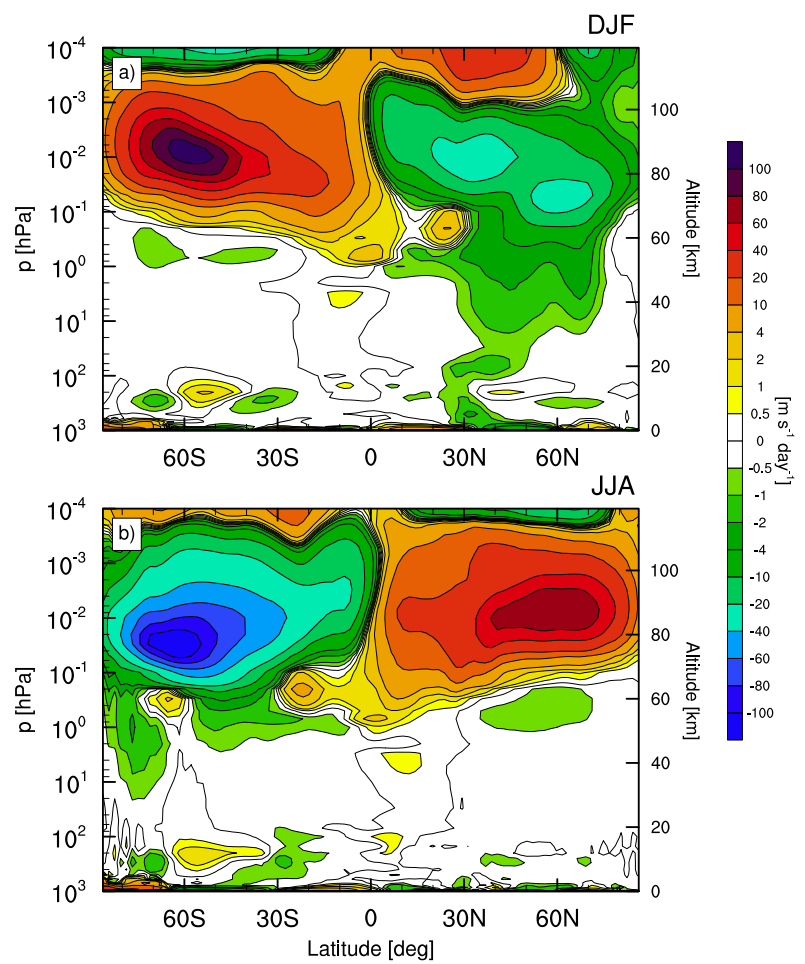

FIG. 1. Climatology of total nonresolved wave drag computed as the residual of the TEM zonal momentum equation $[X]$ for the 145-yr CTL-TR simulation averaged over (a) DJF and (b) JJA. Color contour intervals are $\pm(0.5,1,2,4,10,20,40,60,80$, and 100) $\mathrm{m} \mathrm{s}^{-1} \mathrm{day}^{-1}$.

$$
\begin{aligned}
F_{y} & =\rho_{0} a \cos \phi\left(-\left[u^{*} v^{*}\right]+\frac{[u]_{z}\left[v^{*} \theta^{*}\right]}{\left[\theta_{z}\right]}\right), \\
F_{z} & =\rho_{0} a \cos \phi\left(\frac{-\zeta_{a}\left[v^{*} \theta^{*}\right]}{\left[\theta_{z}\right]}-\left[u^{*} w^{*}\right]\right), \text { and } \\
\nabla \cdot \mathbf{F} & =\frac{1}{a \cos \phi} \frac{\partial\left(F_{y} \cos \phi\right)}{\partial \phi}+\frac{\partial F_{z}}{\partial z} .
\end{aligned}
$$

Given that not all parameterized wave drags were saved in the simulations, the "nonresolved wave drag" is defined as the residual of the TEM zonal momentum equation $[X]$. Figures $1 \mathrm{a}$ and $1 \mathrm{~b}$ show the climatology of nonresolved wave drag $[X]$ from the CTL-TR experiment averaged over DecemberFebruary (DJF) and June-August (JJA). Compared to the previous analysis of parameterized GWD in WACCM [Richter et al. (2010), see their Fig. 6d], it can be seen that the total nonresolved wave drag calculated from Eq. (1) (Fig. 1a) is comparable to the total parameterized GWD, which includes both orographic and nonorographic GWD. In addition, the westerly (easterly) nonresolved wave drag dominates the summer (winter) mesosphere, which is consistent 
with filtering of the easterly (westerly) GWD by stratospheric easterlies (westerlies) in the summer (winter) (Figs. 1a,b). This result indicates that the nonresolved wave drag is mainly attributed to parameterized GWD.

According to the TEM zonal momentum budget [Eq. (1)], the easterly (westerly) wave drag exerted on the mean flow leads, through the Coriolis force, to a poleward and downward (upward and equatorward) residual circulation in high latitudes, resulting in adiabatic warming (cooling) over this region. To diagnose the residual circulation induced by the resolved wave drag, we computed the mass streamfunction using the downward control principle (Haynes et al. 1991) as

$$
\Psi_{\mathrm{rw}}(\phi, p)=\frac{\cos \phi}{g} \int_{p}^{0}\left\{\frac{\left(\rho_{0} a \cos \phi\right)^{-1} \nabla \cdot \mathbf{F}}{f-(a \cos \phi)^{-1}([u] \cos \phi)}\right\} d p,
$$

where $g$ is the acceleration due to gravity. The mass streamfunction for the nonresolved wave drag $\left(\Psi_{\text {nrw }}\right)$ is deduced by the difference between the total mass streamfunction $\Psi(\phi, p)=-\cos \phi / g \int_{p}^{0}[v]^{\dagger} d p^{\prime}$, and the downward control streamfunction $\Psi_{\text {rw }}$ [Eq. (5)], similar as in (Karpechko and Manzini 2012), as follows:

$$
\Psi_{\text {nrw }}(\phi, p)=\frac{\cos \phi}{g}\left\langle\int_{p}^{0}[v]^{\dagger} d p^{\prime}-\int_{p}^{0}\left\{\frac{\left(\rho_{0} a \cos \phi\right)^{-1} \nabla \cdot \mathbf{F}}{f-(a \cos \phi)^{-1}([u] \cos \phi)}\right\} d p\right\rangle .
$$

In addition, the total dynamical heating rates (i.e., temperature tendency $[\theta]_{t}$ due to dynamical processes) are computed by rearranging the TEM thermodynamic balance [Eq. (2)], similar as in (e.g., Dunkerton et al. 1981; Orr et al. 2013), as follows:

$$
\begin{aligned}
{\left[Q_{\mathrm{dyn}}\right]^{\theta}=} & -\frac{1}{\rho_{0}}\left\{\rho_{0}\left(\frac{\left[v^{*} \theta^{*}\right]\left[\theta_{\phi}\right]}{a[\theta]_{z}}+\left[w^{*} \theta^{*}\right]\right)\right\}_{z} \\
& -\frac{1}{a}[v]^{\dagger}[\theta]_{\phi}-[w]^{\dagger}[\theta]_{z} .
\end{aligned}
$$

The first term on the right-hand side of (7) is a contribution to dynamical heating from nonquasi-geostrophic motions (i.e., eddy-heat flux term). This term is generally much smaller than the other two terms on the righthand side of this equation. Hence, changes in total dynamical heating rates $\left[Q_{\mathrm{dyn}}\right]^{\theta}$ mainly result from the advective terms $\left(-a^{-1}[v]^{\dagger}[\theta]_{\phi}-[w]^{\dagger}[\theta]_{z}\right)$. The shortwave and longwave radiative heating rates are the primary components of the total diabatic heating source $\left[Q_{\text {dia }}\right]$ in the middle atmosphere. These radiative heating rates were diagnosed directly from the model. To compare the dynamical heating with radiative heating from the model, the result of $\left[Q_{\mathrm{dyn}}\right]^{\theta}$ is converted to absolute temperature as $\left[Q_{\mathrm{dyn}}\right]=$ $\left[Q_{\mathrm{dyn}}\right]^{\theta}\left(p / p_{0}\right)^{R / C_{p}}$, where $R$ is the gas constant of air and $C_{p}$ is the specific heat capacity. Furthermore, the dynamical heating rates attributed to resolved and nonresolved wave forcing are computed by first calculating the vertical residual velocity for different type of waves as $[w]_{(\mathrm{rw}, \mathrm{nrw})}^{\dagger}=(g H / p a \cos \phi) \Psi_{(\mathrm{rw}, \mathrm{nrw}) \phi}$, and then these values are used to calculate the dynamical heating rates from the vertical advection terms in Eq. (7).
To investigate in situ wave generation in the MLT via instability of the mean states, the meridional gradient of quasigeostrophic potential vorticity $(\mathrm{PV}),[q]_{y}$, in spherical coordinates (Matsuno 1970) is calculated as

$$
\begin{aligned}
{[q]_{y}=} & \frac{1}{a}[q]_{\phi}=\beta-\frac{1}{a^{2}}\left\{\frac{1}{\cos \phi}([u] \cos \phi)_{\phi}\right\}_{\phi} \\
& -\frac{f^{2}}{\rho_{0}}\left(\frac{\rho}{N^{2}}[u]_{z}\right)_{z}
\end{aligned}
$$

where $\beta$ is the meridional gradient of Coriolis parameter and $N$ is the Brunt-Väisälä frequency. To estimate the effects of different wind structures on the source of instability, the relative contributions of meridional (barotropic) terms $-a^{-2}\left\{\cos \phi^{-1}([u] \cos \phi)_{\phi}\right\}_{\phi}$ and vertical (baroclinic) terms $-f^{2} \rho_{0}^{-1}\left(\rho N^{-2}[u]_{z}\right)_{z}$ of $[q]_{y}$ are also examined separately.

\section{Ozone response to anthropogenic forcing}

Before analyzing the stratosphere and MLT responses to the Antarctic ozone hole, we first examine the global changes in stratospheric ozone in response to natural and anthropogenic forcing factors under the RCP8.5 scenario and then quantify the total southern polar-cap ozone changes during the Antarctic ozone hole period in the model.

\section{a. Global ozone responses}

The evolution of ozone in response to natural forcing factors (CTL-TR, green solid curves) and anthropogenic forcing factor under the RCP8.5 scenario (GHGODSTR, solid red curves) from 1955 to 2099 is illustrated in 
(a) SH Lower Stratosphere - Annual [50 hPa, 30S-60S]

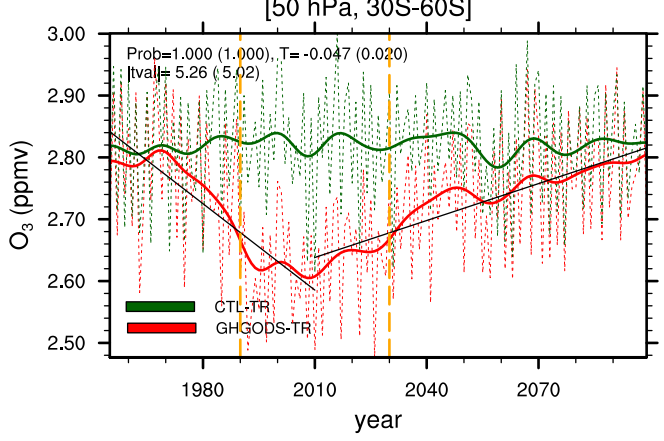

(c) SH Polar Stratosphere - October

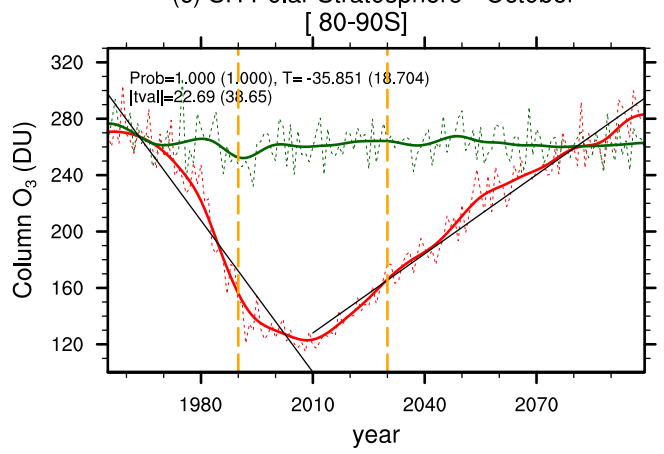

(b) NH Lower Stratosphere - Annual

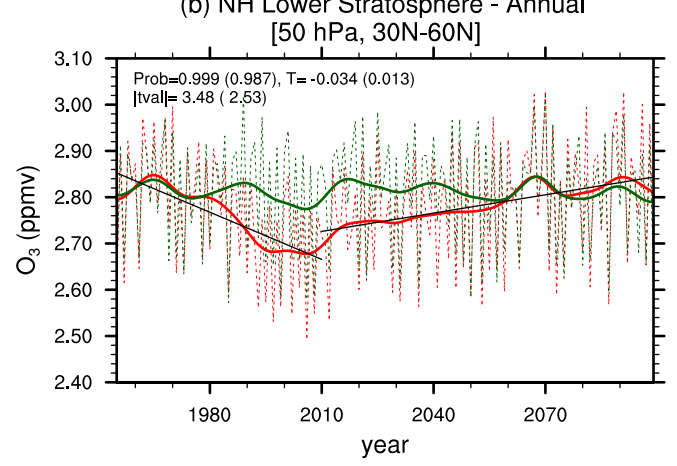

(d) NH Polar Stratosphere - March

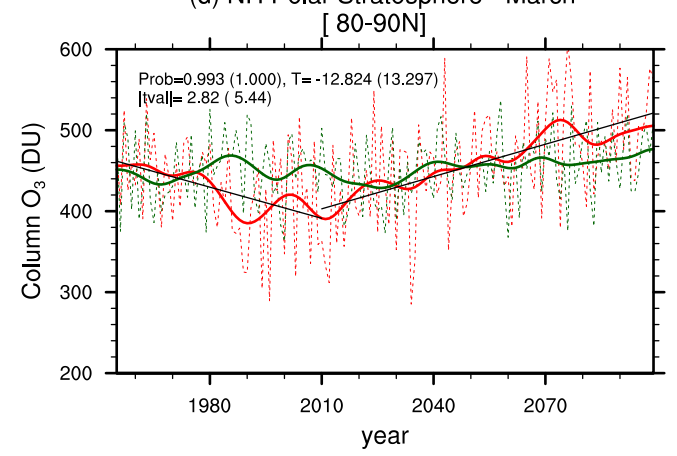

FIG. 2. Evolution of zonal-mean ozone from the CTL-TR (green) and GHGODS-TR (red) simulations for (a) $50 \mathrm{hPa}, 30^{\circ}-60^{\circ} \mathrm{S}$; (b) $50 \mathrm{hPa}, 30^{\circ}-60^{\circ} \mathrm{N}$; (c) column ozone, $80^{\circ}-90^{\circ} \mathrm{S}$; and (d) column ozone, $80^{\circ}-90^{\circ} \mathrm{N}$. (a), (b) Annual means, (c) the October mean, and (d) the March mean. Thick curves are smoothed versions of the thin curves, calculated by applying a 1-2-1 filter iteratively 30 times (see Waugh et al. 2009). Solid lines for the trend lines represent trends found to be more than $95 \%$ statistically significant. The probability (prob), slope per decade $(T)$, and $t$-statistic values of the trends from 1955 to 2010 (2011-99) are shown with (without) the parentheses. Vertical orange dashed lines indicate the time frame of maximum Antarctic ozone loss.

Figs. 2a-d. In general, the ozone decrease in the GHGODS-TR simulation occurred steadily from 1955 to 2010 and increase throughout the twenty-first century, consistent with previous chemistry-climate model (CCM) studies (e.g., Eyring et al. 2013). The annualmean evolution of ozone in the midlatitude lower stratosphere differs between hemispheres (Figs. 2a,b). The anthropogenic-induced changes in the southern midlatitude ozone by 2010 are much more skewed, and stronger, compared to the northern midlatitude ozone. In 2010, anthropogenic-induced ozone in the southern midlatitude average was significantly lower $(\sim 8 \%)$ than 1980s values.

Figures $2 \mathrm{c}$ and $2 \mathrm{~d}$ show the time evolution of spring column ozone in both hemispheres. In response to anthropogenic forcing, the total spring column ozone in both hemispheres decreases from 1950s values to minimum values in 2010 and then increase to approximately 1980s values by 2060 in the SH or by 2040 in the NH (Figs. 2c,d). The rate of decline of the springtime polar column ozone from 1955 to 2010 is much more rapid and larger in the $\mathrm{SH}$ than in the $\mathrm{NH}[-35.88$ and $-12.82 \mathrm{DU}$ $(10 \mathrm{yr})^{-1}$, respectively], consistent with the earliest findings of CCM studies (e.g., Austin and Wilson 2006; Waugh et al. 2009; Eyring et al. 2013). The deep Antarctic ozone hole in the anthropogenic forcing simulation occurs from 1990 to 2030, with column ozone concentration reduced down to $\sim 130$ DU.

\section{b. Antarctic ozone hole}

Guided by the evolution of spring column ozone in the SH (Fig. 2c), we focus our analysis in the period from 1990 to 2030, during which the deep Antarctic ozone hole is present in the model simulation. Hereafter, all transient simulation responses shown in the rest of the manuscript are in reference to the averaged period of 1990-2030. The differences in global, monthly mean, and zonal-mean total column ozone between GHGODSTR and CTL-TR are shown in Fig. 3a. The largest ozone decrease is found in the $\mathrm{SH}$ polar region during austral spring and peaks in October-November, with a decrease of $\sim 130$ DU. However, during the summer, the total 
(a) Total Column Ozone Difference [DU]

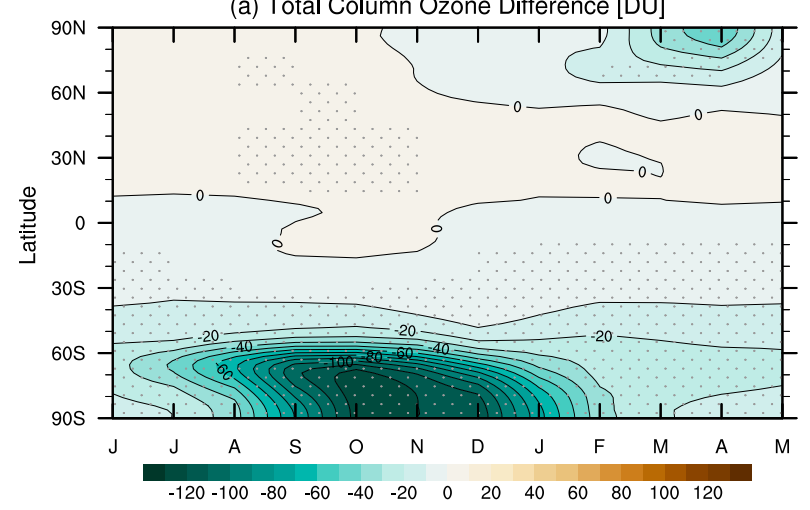

(b) O3 Mixing Ratio Difference [\%]

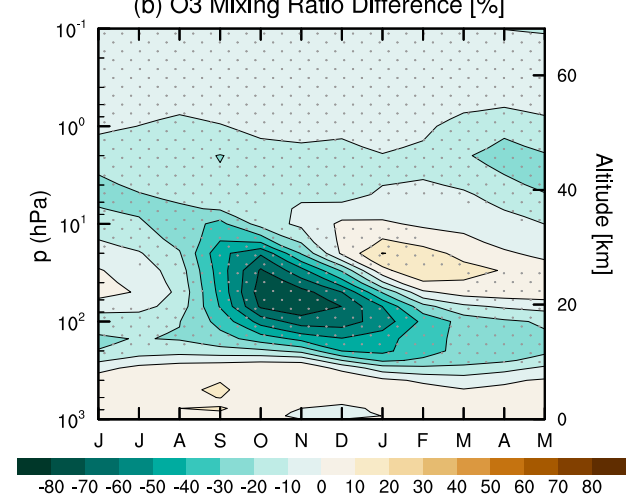

FIG. 3. (a) Zonal-mean, monthly mean total column ozone differences between GHGODS-TR and CTL-TR averaged over the years 1990-2030 as a function of month. The contour interval is $10 \mathrm{DU}$ and colors range from 0 to \pm 120 DU. (b) Differences in the polar-cap average $\left(90^{\circ}-70^{\circ} \mathrm{S}\right)$ ozone concentration as a function of month and pressure. The contour interval is $10 \%$ and colors range from $0 \%$ to $\pm 80 \%$. Stippling indicates regions where the change exceeds the $95 \%$ significance level based on a two-tailed Student's $t$ test.

column ozone decrease is limited up to 10-30 DU. In the $\mathrm{SH}$ midlatitudes $\left(30^{\circ}-60^{\circ} \mathrm{S}\right)$, the column ozone decreases by up to $20 \mathrm{DU}$ throughout the seasons. This seasonal variation of the Antarctic ozone loss is in good agreement with previous CCM studies (e.g., Manzini et al. 2003; Marsh et al. 2013; Keeble et al. 2014).

Figure $3 b$ shows the percentage change of the zonalmean ozone mixing ratio averaged over the polar cap $\left(70^{\circ}-90^{\circ} \mathrm{S}\right)$. The strong ozone loss begins in September at $20 \mathrm{hPa}$ and descends in altitude over time. The largest ozone loss occurs during October-November with a maximum of $77.4 \%$ ozone destroyed at $50 \mathrm{hPa}$. The ozone hole is followed by a distinct increase in ozone mixing ratios in the mid stratosphere during summer through autumn, peaking in February at $20 \mathrm{hPa}$. The temporal extent of this positive ozone response from late summer to autumn in the midstratosphere is to a large degree associated with increased downwelling induced by resolved planetary wave drag (see section 4 for detailed analysis).

\section{Middle-atmosphere temperature coupling}

In this section, the impact of the Antarctic ozone hole on the stratosphere and MLT temperatures is examined by discussing the seasonal structure of the temperature responses, the contribution of radiative and dynamical heating components, and the effects of different types of wave drag to the dynamical heating responses.

\section{a. Temperature responses}

Figure 4a shows the zonal-mean, monthly mean temperature differences between GHGODS-TR and CTL-TR, averaged over the polar cap $\left(90^{\circ}-70^{\circ} \mathrm{S}\right)$ as a function of pressure and month. Consistent with previous observations and model studies (e.g., Thompson and Solomon 2002; Manzini et al. 2003; Marsh et al. 2013; Keeble et al. 2014), the polar stratospheric ozone loss leads to a strong seasonal temperature response in the lower stratosphere. Consistent with the negative ozone response shown in Fig. 3b, the strong cooling of the lower polar stratosphere begins in September when sunlight activates the catalytic cycles to rapidly deplete ozone and continues until April. The maximum cooling occurs from November to December, when the polar-cap average temperature response at $70 \mathrm{hPa}$ is up to $16 \mathrm{~K}$. In addition, there is also a statistically significant positive temperature response in the middle to upper stratosphere beginning in November and persisting through February and March, which is associated with enhanced downwelling and dynamically induced ozone increase near $10 \mathrm{hPa}$ over the polar cap (Fig. 3b and see section $3 \mathrm{~b}$ for further details). The maximum warming over this region occurs in December, during which temperatures at $7 \mathrm{hPa}$ increase by $4 \mathrm{~K}$.

In contrast to the stratosphere, the mesosphere begins to warm from October to December (Fig. 4a). The maximum warming occurs in November, with temperature increases of $\sim 8 \mathrm{~K}$ at $0.01 \mathrm{hPa}$ around the mesopause. On the other hand, the lower thermosphere cools by up to $14 \mathrm{~K}$ above $0.001 \mathrm{hPa}$ throughout the seasons. In addition, Fig. 4 also includes the zonal-mean temperature responses from the timeslice experiments by isolating the effects of the ozone depletion (Fig. 4b) and increased GHGs (Fig. 4c). The differences between these temperature responses confirm that the polar stratospheric ozone loss is largely responsible for spring to summer temperature changes in the stratosphere and MLT regions (Fig. 4b). It is also worth noting that the significant cooling of the lower thermosphere $\left(10^{-3}\right.$ and $10^{-4} \mathrm{hPa}$ ) between October and December is partly caused by the increased GHG concentration (Fig. 4c). 
(a) GHGODS-TR minus CTL-TR

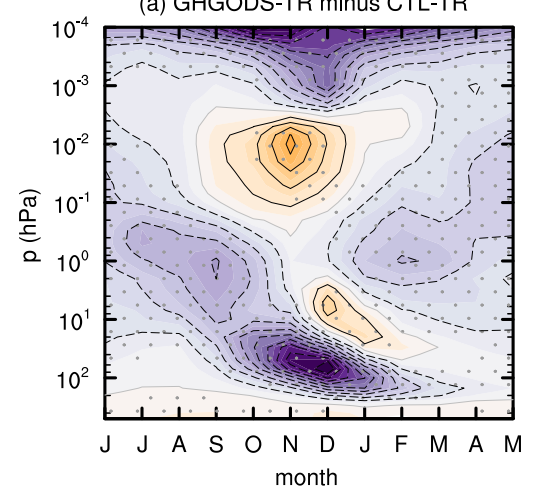

(b) REF-TS minus GHG2010-TS

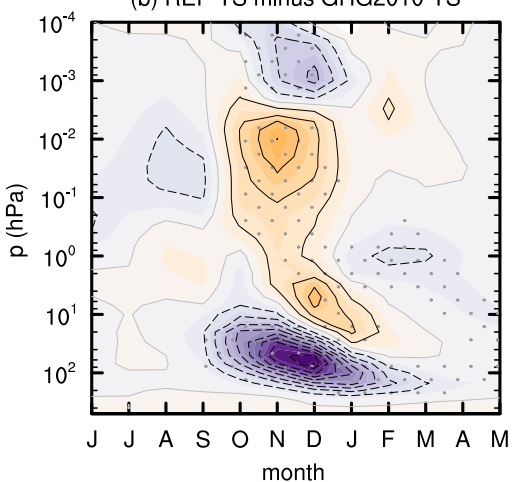

(c) REF-TS minus ODS2010-TS

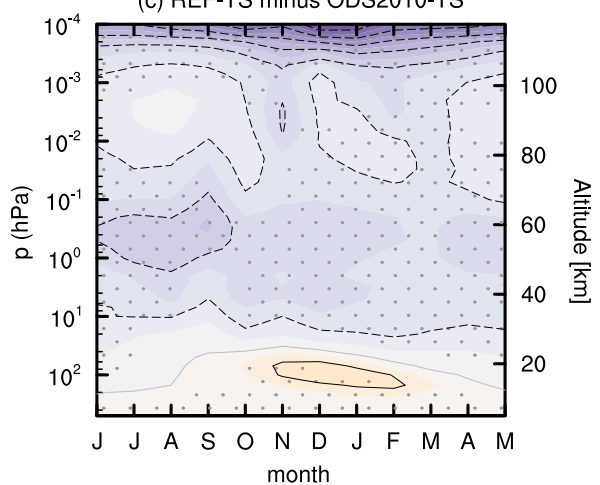

$[\mathrm{K}]$

FIG. 4. (a) Polar-cap-average $\left(90^{\circ}-70^{\circ} \mathrm{S}\right)$ temperature differences between GHGODS-TR and CTL-TR averaged over the 1990-2030 period as a function of month and pressure. (b),(c) As in (a), but for the timeslice experiments: (b) REF-TS minus GHG2010-TS (impact of ozone only) and (c) REF-TS minus ODS2010-TS (impact of GHGs only). The contour interval is $2 \mathrm{~K}$, solid (dashed) contours represent positive (negative) changes, and colors range from 0 to $\pm 18 \mathrm{~K}$. The zero contour is shown with solid gray lines. Stippling indicates regions where the change exceeds the $95 \%$ significance level based on a two-tailed Student's $t$ test.

\section{b. Dynamical and radiative contributions to temperature coupling}

To examine the contribution of dynamics and radiation to the temperature responses, we computed the dynamical, shortwave, and longwave heating-rate responses from both the transient (Figs. 5a-d) and timeslice simulations (Fig. S1 in the supplemental material). Here we focus our analysis on December, since the stratospheric temperature changes resulting from the Antarctic ozone hole are at their maximum in this period. Qualitatively similar results are also found in November (not shown).

Figure 5 shows a meridional cross section of the zonalmean temperature differences between GHGODS-TR and CTL-TR as well as the dynamical and radiative (short- and longwave) heating-rate differences. In the lower to midstratosphere (between 250 and $10 \mathrm{hPa}$ ), temperature decreases significantly by $\sim 16 \mathrm{~K}$ (Fig. 5a). This cooling is caused by a reduction of shortwave heating rates (up to $0.6 \mathrm{~K} \mathrm{day}^{-1}$ ) as a result of ozone destruction via catalytic chemical reactions (Fig. 5c). This result is comparable to a coupled CCM study by Keeble et al. (2014), showing a maximum reduction of shortwave heating rates by $\sim 0.6 \mathrm{~K} \mathrm{day}^{-1}$ in December. In addition, the cooling in the lower to midstratosphere is enhanced by anomalous dynamical cooling (up to $-0.25 \mathrm{~K} \mathrm{day}^{-1}$ ) induced by anomalous upwelling between $\sim 300$ and $\sim 100 \mathrm{hPa}$ (see solid contour lines in Fig. 5b). This is in agreement with previous findings by Orr et al. (2013), which show that the radiative cooling in the lower stratosphere is enhanced by a reduction in dynamical heating rates. This overall lower-stratospheric temperature response is due mainly to the effects of the stratospheric ozone depletion (Figs. S1a-d).

An increase of the mid- to upper-stratospheric polar temperatures (between 10 and $1 \mathrm{hPa}$ ) by up to $\sim 5 \mathrm{~K}$ is due to anomalous dynamical heating induced by anomalous polar downwelling (Fig. 5b) and to a smaller degree by anomalous shortwave heating due to increased ozone concentrations (Fig. 3b). The warming above the lower-stratospheric cooling is consistent with the previous CCM studies, which is attributed to the Antarctic ozone hole (e.g., Manzini et al. 2003; Lossow et al. 2012; Marsh et al. 2013; Keeble et al. 2014). In addition, the dynamical warming between 0.7 and $0.1 \mathrm{hPa}$ is dampened by radiative cooling, resulting in insignificant anomalous cooling over this region. Further analysis by separating the effects of stratospheric ozone depletion and increased GHGs show that this radiative cooling is mainly attributed to increased GHGs (Figs. S1e,f).

In the mid- to upper mesosphere $(0.7$ to $0.002 \mathrm{hPa})$, a significant temperature increase by $\sim 10 \mathrm{~K}$ is associated with the dynamical warming induced by anomalous polar downwelling (Fig. 5b). On the other hand, the anomalous cooling in the lower thermosphere (0.001$0.0001 \mathrm{hPa}$ ) is caused by a combination of anomalous dynamical cooling (up to $5 \mathrm{~K} \mathrm{day}^{-1}$ ) induced by anomalous polar upwelling (Fig. 5b) and anomalous radiative cooling due to increased GHGs (Fig. 5d and Figs. S1e,h). The effects of increased GHG concentrations also explain the significant temperature decreases in the MLT regions from late summer to late winter.

To quantify the effects of resolved and nonresolved wave drag on the dynamical heating rates, we performed a downward control analysis [Eqs. (5) and (6)] to calculate 
(a) T Response

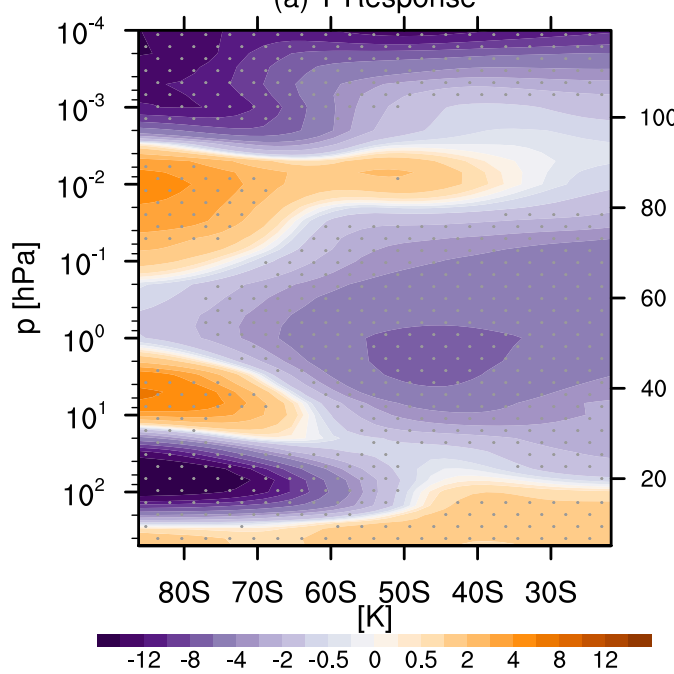

(c) SWR Heating

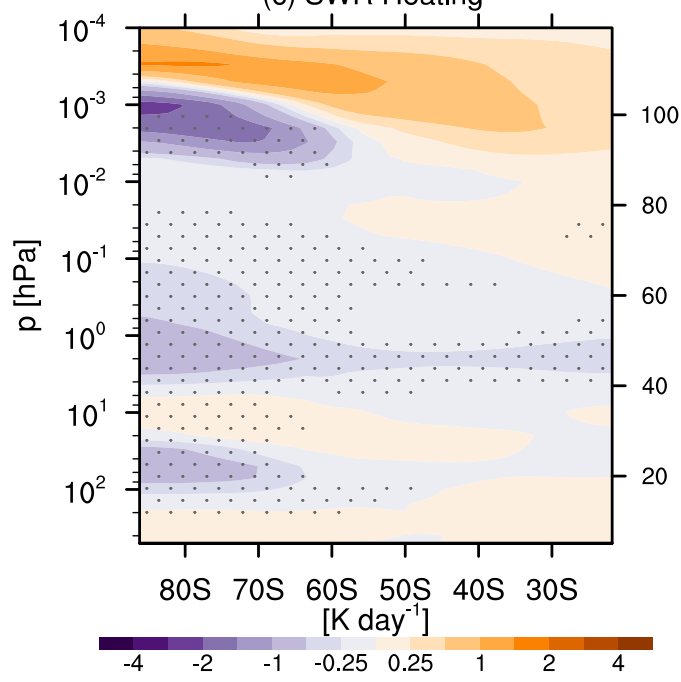

(b) Tot. Dyn. Heating, $\Psi_{\text {TOT }}$

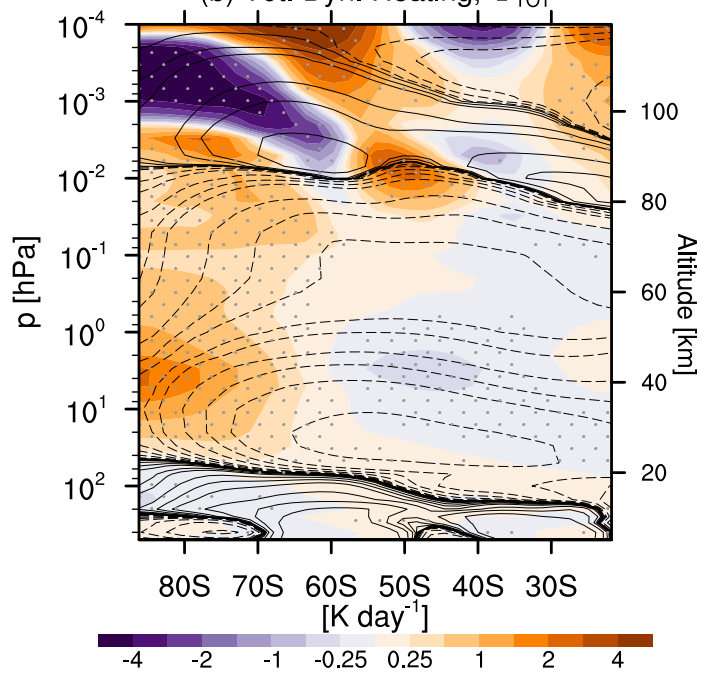

(d) LWR Heating

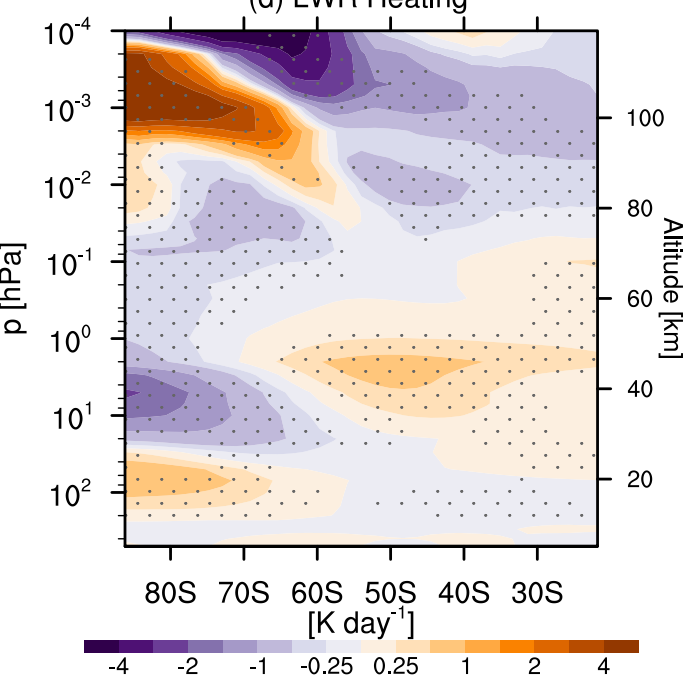

FIG. 5. December zonally averaged temperature and heating-rate differences between GHGODS-TR and CTLTR averaged over the 1990-2030 period as a function of latitude and pressure. (a) Temperature (K), (b) total dynamical heating rate $\left\{\left[Q_{\text {dyn }}\right]\right.$ see Eq. (8), $\left.\mathrm{Kday}^{-1}\right\}$, (c) shortwave heating rate $\left(\mathrm{K} \mathrm{day}^{-1}\right)$, and (d) longwave heating rate $\left(\mathrm{K} \mathrm{day}^{-1}\right)$. Contours in (b) denote the residual mass streamfunction $(\Psi)$ at intervals of $\pm\left\{1 \times 10^{5} \times\right.$ $[0.01,0.05,0.1,0.5,1,2,4,8,16,32, \ldots]\} \mathrm{kg} \mathrm{s}^{-1}$ with solid (dashed) contours indicating upwelling (downwelling) of air parcels in a counterclockwise (clockwise) direction. Stippling indicates regions where the change exceeds the $95 \%$ significance level. For clarity, a nonlinear color scale is used for temperature and heating-rate differences [interval of $0.25 \mathrm{~K}\left(0.25 \mathrm{~K} \mathrm{day}^{-1}\right)$ for absolute values $<1 \mathrm{~K}\left(1 \mathrm{~K} \mathrm{day}^{-1}\right)$ and interval of $1 \mathrm{~K}\left(1 \mathrm{~K} \mathrm{day}^{-1}\right)$ for absolute values $\left.>1 \mathrm{~K}\left(1 \mathrm{~K} \mathrm{day}^{-1}\right)\right]$.

the separate contributions to residual circulation and dynamical heating from different types of wave drag. Figure 6 shows the meridional cross section of dynamical heating rates and residual circulation from total (Fig. 6a), resolved (Fig. 6b), and nonresolved (Fig. 6c) wave contributions. The anomalous dynamical cooling from the upper troposphere to lower stratosphere $(\sim 250-100 \mathrm{hPa}$, Fig. 5b) is associated with anomalous upwelling induced by resolved waves
[Fig. 6b, consistent with Orr et al. (2013)]. Furthermore, the anomalous dynamical heating in the mid- to upper stratosphere (50-1 hPa, Fig. 5b) can be explained by anomalous dynamical heating induced by both resolved waves $\left(0.5-2 \mathrm{~K}\right.$ day $^{-1}$ between 50 and $\left.1 \mathrm{hPa}\right)$ and nonresolved waves $\left(0.5-1.5 \mathrm{~K} \mathrm{day}^{-1}\right.$ between 5 and $1 \mathrm{hPa}$ ). This indicates that both the resolved and nonresolved wave drag play crucial roles in determining the anomalous dynamical heating in the mid- to upper 

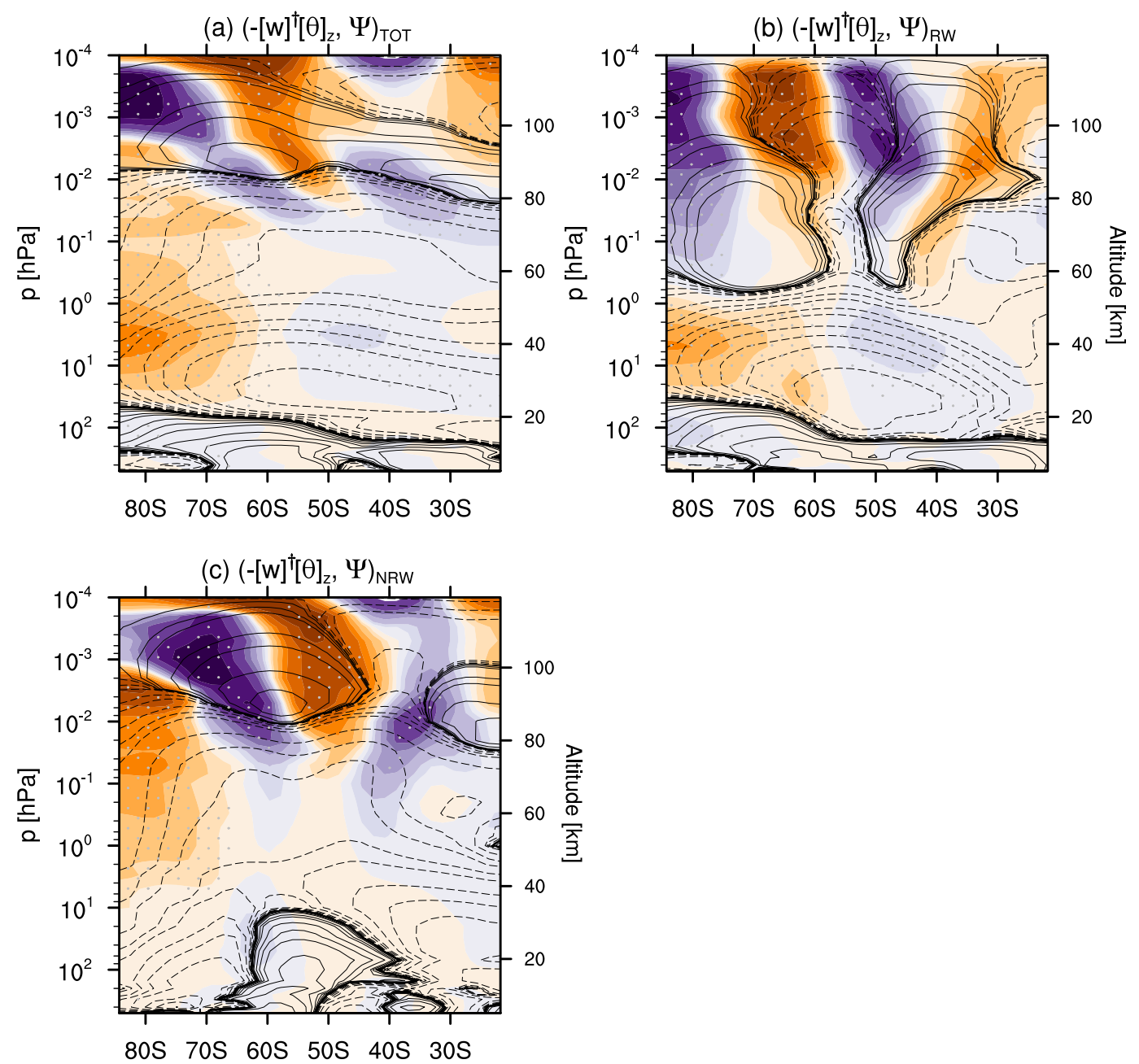

[K/day]

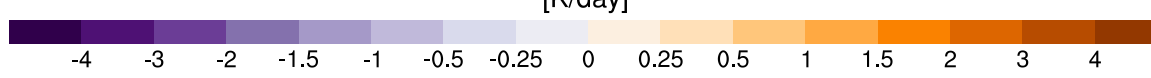

FIG. 6. December zonally averaged dynamical heating-rate and residual circulation differences between GHGODS-TR and CTL-TR averaged for the 1990-2030 period as a function of latitude and pressure. (a) Total [w] advection, (b) $[\mathrm{w}]^{\dagger}$ advection from resolved waves, and (c) $[\mathrm{w}]^{\dagger}$ advection from nonresolved waves. Contour intervals are as in Fig. $5 \mathrm{~b}$ for the heating-rate responses and $\pm\left\{1 \times 10^{5} \times[0.01,0.05,0.1,0.5,1,2,4,8,16,32, \ldots]\right\} \mathrm{kg} \mathrm{s}^{-1}$ for residual (mass) streamfunction responses. Solid (dashed) contours of $\Psi$ indicate clockwise (counterclockwise) circulation with upwelling (downwelling) in the Antarctic regions. Stippling indicates regions where the change exceeds the $95 \%$ significance level.

stratosphere in response to the ozone hole, which was not shown in previous studies.

Furthermore, the adiabatic warming in the mesosphere $(0.1-0.003 \mathrm{hPa}$, Fig. $5 \mathrm{~b})$ is caused by anomalous downwelling induced by nonresolved waves (Fig. 6c). Our analysis for the first time shows that this anomalous downwelling is dampened by $\sim 50 \%-60 \%$ by the effects of the anomalous upwelling induced by resolved wave drag (Fig. 6b). The net of the two effects yields a weakening of the summer upwelling in the mesosphere, which is consistent with positive trends in
SH summer mesospheric temperatures shown by Smith et al. (2010). In the lower thermosphere (0.001$0.0001 \mathrm{hPa}$ ), the anomalous cooling is not only attributed to anomalous nonresolved wave-driven upwelling [as shown by Smith et al. (2010)] but also to the effects of anomalous upwelling induced by resolved wave drag (Figs. 6b,c). This combined effect leads to a weakening of the SH summer downwelling above $0.001 \mathrm{hPa}$ and, thus, is consistent with decreased SH summer temperatures in the lower thermosphere (Fig. 5a). 
(a) U: GHGODS-TR minus CTL-TR

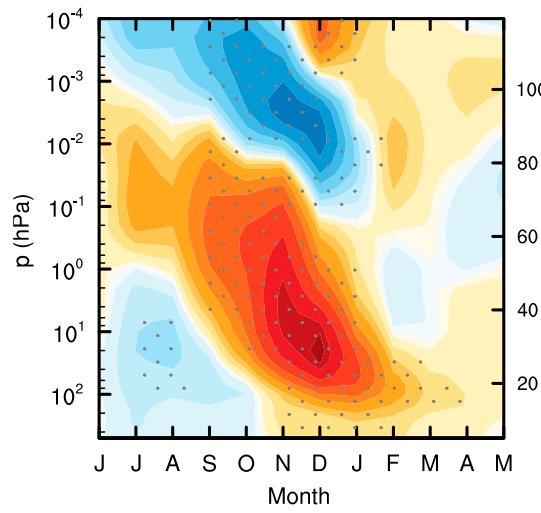

(d) Total Wave Drag

GHGODS-TR minus CTL-TR

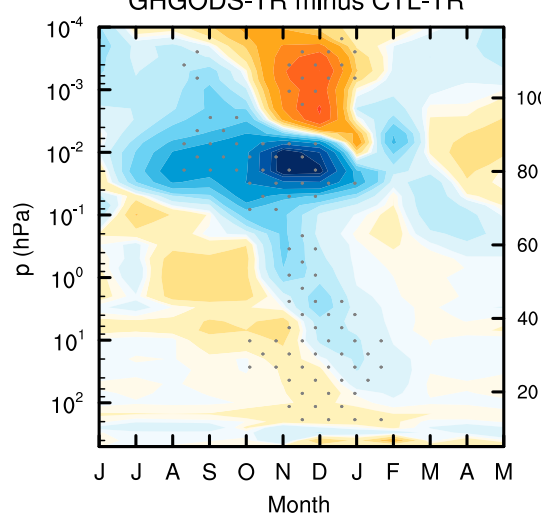

(b) U: REF-TS minus GHG2010-TS

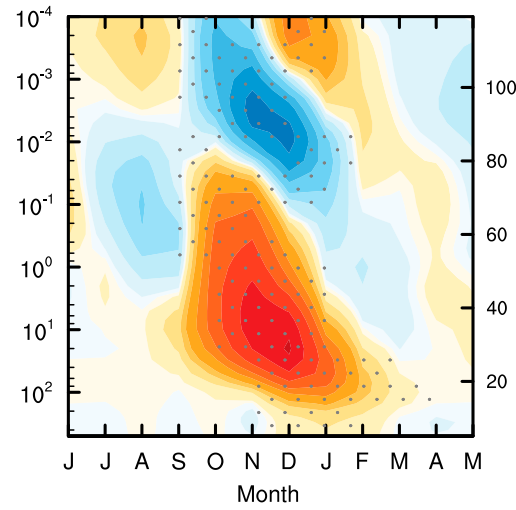

(e) Resolved Wave Drag GHGODS-TR minus CTL-TR

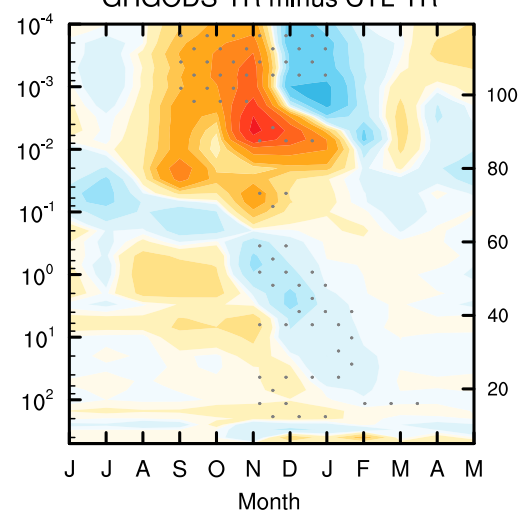

(c) U: REF-TS minus ODS2010-TS

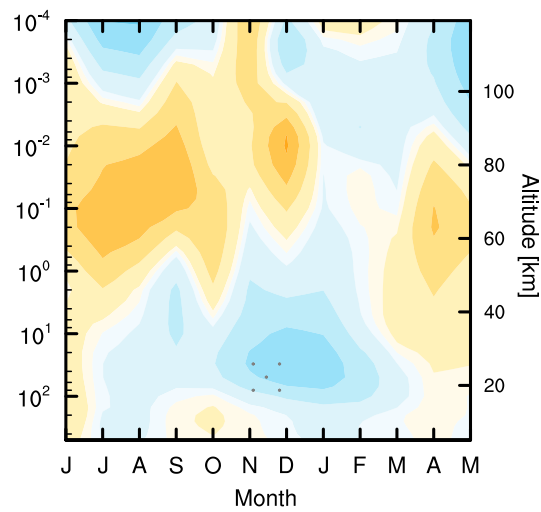

(f) Non-resolved Wave Drag GHGODS-TR minus CTL-TR

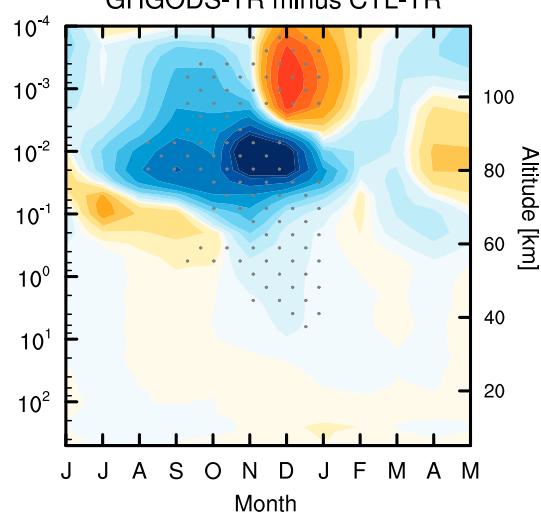

$[\mathrm{m} / \mathrm{s}] ;[\mathrm{m} / \mathrm{s} /$ day $]$

$\begin{array}{lllllllllllllllllllll}-20 & -18 & -14 & -10 & -7 & -5 & -3 & -2 & -1 & -0.25 & 0 & 0.25 & 1 & 2 & 3 & 5 & 7 & 10 & 14 & 18 & 20\end{array}$

FIG. 7. (a) Zonal-mean, monthly mean zonal wind differences between GHGODS-TR and CTL-TR averaged from $75^{\circ}$ to $55^{\circ} \mathrm{S}$, and averaged for the 1990-2030 period, as a function of month and pressure. (b),(c) As in (a), but for the timeslice experiments: (b) REF-TS minus GHG2010-TS (impact of ozone only) and (c) REF-TS minus ODS2010-TS (impact of GHGs only). (d)-(f) Wave drag $\left(\mathrm{m} \mathrm{s}^{-1}\right.$ day $\left.^{-1}\right)$ differences between GHGODS-TR and CTL-TR divided into contributions from (d) total waves, (e) resolved waves, and (f) nonresolved waves. Stippling indicates regions where the change exceeds the $95 \%$ significance level.

\section{Middle atmosphere zonal wind coupling}

This section focuses on the mechanisms responsible for maintaining downward propagation of the zonalmean wind anomalies in the MLT due to the Antarctic ozone hole. We begin by discussing the vertical coupling of the zonal-mean wind anomalies, the roles of resolved and nonresolved wave drag in maintaining downward propagation of zonal wind responses and the dynamical origin of the positive resolved wave responses in the MLT.

\section{a. Downward propagation of the zonal wind anomalies}

Figure 7a shows the zonal-mean, monthly mean zonal wind response averaged over $75^{\circ}-55^{\circ} \mathrm{S}$ between GHGODSTR and CTL-TR. Consistent with the increased meridional temperature gradient (Fig. 5a), the stratospheric westerlies are significantly strengthened from midspring to late summer, with maximum changes of nearly $20 \mathrm{~m} \mathrm{~s}^{-1}$ near $20 \mathrm{hPa}$ in December. This is indicated by the downward propagation of the westerly wind anomalies from the lower mesosphere to the surface (Fig. 7a). The strengthening of the westerlies has been shown to cause a delay in the final vortex breakdown by about several weeks (e.g., Karpechko et al. 2010; Lossow et al. 2012; Keeble et al. 2014).

In conjunction with stratospheric zonal wind changes occurs a strengthening of the prevailing easterlies in the mesosphere from late spring to early summer. This is indicated by a downward propagation of the easterly wind anomalies from the lower thermosphere to lower mesosphere, with maximum changes of nearly $15 \mathrm{~m} \mathrm{~s}^{-1}$ 
near $0.005 \mathrm{hPa}$ in December. Stronger summer easterlies in the mesosphere are consistent with the simulated negative trends of the summer mesospheric winds in the SH found by Smith et al. (2010) and the observed persistence of the winter mesospheric wind condition into summer during the ozone hole period (Venkateswara Rao et al. 2015). In addition, there is a strengthening of prevailing westerlies in the lower thermosphere (between 0.001 and $0.0001 \mathrm{hPa}$ ) during the period of the strongest Antarctic ozone hole in the model. This is associated with a significant downward propagation of the westerly wind anomalies from the lower thermosphere to the upper mesosphere from November to February. The strengthening of the prevailing westerlies in the lower thermosphere during the strongest Antarctic ozone hole in the model is interesting, but needs to be verified by further observational studies. In addition, Fig. 7 includes the zonal-mean wind response from the timeslice experiments by separating the effects of ozone depletion (Fig. 7b) and global warming (Fig. 7c). The differences between the two timeslice simulations confirm that it is indeed the Antarctic ozone hole that is responsible for the downward coupling of the zonalmean wind anomalies in the stratosphere and MLT regions (Figs. 7b,c).

\section{b. Wave-maintained vertical zonal wind coupling}

To understand the mechanisms responsible for maintaining downward propagation of the zonal wind anomalies in the stratosphere and MLT, the total, resolved, and nonresolved wave drag differences between GHGODSTR and CTL-TR are examined (Figs. 7d-f).

In the period of initial (radiative) strengthening of lower-stratospheric winds (from October to late November, Fig. 7a) there is decreased resolved (planetary) wave breaking in the stratosphere indicated by positive westerly wave drag anomalies in the lower through the middle stratosphere (Figs. 7d,e). In particular, the increasing westerly wind above the critical value dampens upward planetary wave activity into the stratosphere, as indicated by anomalous negative vertical EP flux during this period (not shown). This condition can initiate a positive feedback mechanism, in which the strengthened westerlies associated with weaker wave driving can cause further vortex strengthening and induce downward migration of the wind anomalies toward the tropopause [consistent with the mechanism proposed by Orr et al. (2012)]. Conversely, in the summer (from December to late February) the delayed breakdown of the polar vortex allows planetary waves to propagate higher into the stratosphere. This results in increased resolved wave breaking, as diagnosed by anomalous negative EP-flux divergence between $\sim 100$ and $1 \mathrm{hPa}$
(Figs. 7d,e). The strong increase in wave breaking in response to the ozone hole during the austral summer is consistent with Keeble et al. (2014).

The downward propagation of easterly wind anomalies from the lower thermosphere to lower mesosphere is maintained by total easterly wave drag anomalies (Fig. 7d). These total wave drag anomalies are formed by resolved and nonresolved wave drag that have almost similar structures but are opposite in sign (Figs. 7e,f). However, since the contribution from easterly nonresolved wave drag anomalies exceeds that of westerly resolved wave drag anomalies, the sum of the two yields the net easterly wave drag anomalies that preserve the downward propagation of the easterly wind anomalies in the MLT from spring to early summer. The increased easterly nonresolved wave drag during this period is consistent with an increased filtering of the westerly nonresolved wave drag by stratospheric westerly winds (Fig. 7a).

In addition, the downward propagation of westerly wind anomalies in the lower thermosphere from November to February is maintained by the total westerly wave drag anomalies (Fig. 7d). These total westerly wave drag anomalies consist of both nonresolved wave drag (dominant component) and resolved wave drag (Figs. 7e,f). The increased westerly nonresolved waved drag in the lower thermosphere is a result of increased filtering of the easterly nonresolved wave drag by mesospheric easterly winds (Fig. 7a), while the increased westerly resolved wave drag in the lower thermosphere is associated with in situ wave generation in the upper mesosphere via zonal-mean state instabilities (see section $5 \mathrm{c}$ for details). These results for the first time show that both resolved and nonresolved wave drag are important in maintaining the downward propagation of the zonal wind anomalies in the MLT during the ozone hole period.

\section{c. Dynamical origin of the resolved wave drag responses in the $M L T$}

The emergence of pronounced changes in resolved wave drag in the MLT from late spring to early summer (from November to December) is interesting and requires further investigation. One possible mechanism is associated with changes in in situ wave excitation via instability of the background zonal-mean state (Lossow et al. 2012). To examine this process, we analyze the latitude-height cross sections of the meridional gradient of PV response in December along with total resolved wave drag and zonal-mean wind responses (Fig. 8). We focus our analysis on the transient simulation response, since most changes in the zonal-mean wind during a period of strong Antarctic ozone hole in the model are 
(a) PVy \& U

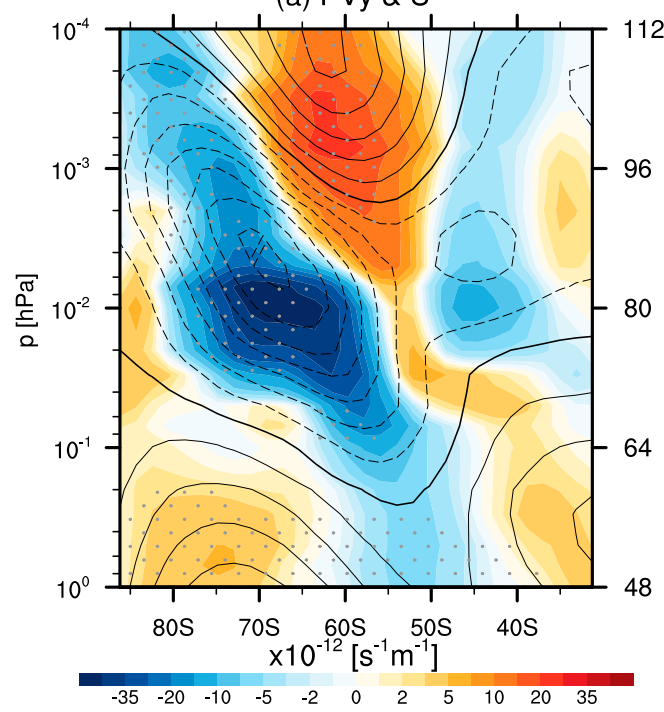

(b) Resolved Wave Drag \& U

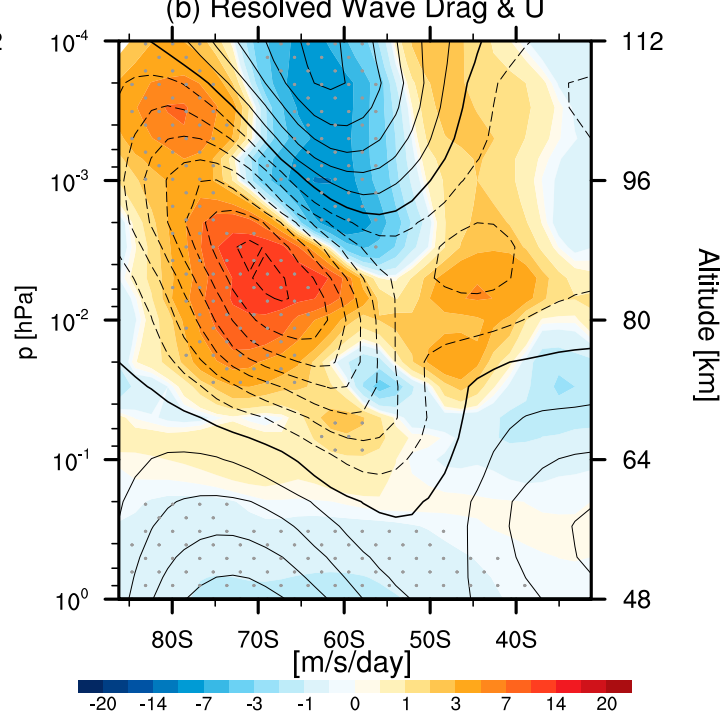

FIG. 8. (a) Meridional PV gradient $[q]_{y}$ (shading, $\times 10^{-12} \mathrm{~s}^{-1} \mathrm{~m}^{-1}$ ) and (b) resolved wave drag (shading, $\mathrm{m} \mathrm{s}^{-1}$ day $^{-1}$ ) differences between GHGODS-TR and CTL-TR averaged for the 1990-2030 period as a function of latitude and pressure in December. The contour lines denote the zonal-mean wind $(U)$ differences between the two simulations (intervals are $2 \mathrm{~m} \mathrm{~s}^{-1}$ ). Stippling indicates regions where the change exceeds the $95 \%$ significance level.

largely due to the stratospheric ozone depletion. The qualitatively similar results are also found in November (not shown).

The negative PV gradient response in December (Fig. 8a) is visible over a wide range of high latitudes, with a maximum response occurring near $0.01 \mathrm{hPa}$. This response strengthens the climatological negative PV gradients in the upper mesosphere and lower thermosphere during early summer. According to Pedlosky (1979), regions where the PV gradient is negative are potentially baroclinically or barotropically unstable and, thus, represent potential sources of in situ wave generation. The stronger easterlies, which have larger and deeper regions of the negative PV gradients, coincide with a region of positive EP-flux divergence anomalies (Fig. 8b). This condition indicates that the westerly resolved wave drag anomalies in the upper mesosphere are locally generated via instability of the zonal-mean state [consistent with Lossow et al. (2012)]. The types of instability responsible for this in situ wave excitation in the upper mesosphere could be a mix of barotropic and baroclinic processes (e.g., Plumb 1983; Garcia et al. 2005; Riggin et al. 2006). To examine this, we decomposed the PV gradient responses into contributions of barotropic (i.e., meridional curvature) and baroclinic (i.e., vertical shear and curvature) terms of the meridional PV gradient equation (Fig. S2 in supplemental material). It should be noted that the barotropic instability is associated with $\mathrm{PV}$ gradient changes of sign between different latitudes, due to meridional wind curvature $\left([u]_{\phi \phi}\right)$, while baroclinic instability is associated with PV gradient changes of sign between the lower and upper levels, due to vertical wind structure $\left(\rho N^{-2}[u]_{z}\right)$ (Pedlosky 1979). Our results show quantitatively that both changes in vertical shear and meridional curvature of the zonal-mean wind appear to be largely responsible for the negative PV gradient response in this region (Fig. S2). This indicates that in situ wave generation in the upper mesosphere during the strongest Antarctic ozone hole in the model is not solely associated with baroclinic instability [as suggested by Lossow et al. (2012)], but also with barotropic instability.

To investigate which type of waves is responsible for the resolved wave drag response in the upper mesosphere, we decompose the resolved wave drag response into different zonal wavenumber $(k)$ contributions. Figure 9 shows latitude-height cross sections of the resolved wave drag differences divided into contributions from planetary-scale waves $k=1$, planetary-scale waves $k=2-3$, and synoptic-scale waves $(k>3)$, with the associated EP-flux vectors superimposed. Comparing resolved wave drag responses from total wavenumbers (Fig. 8b) and to planetary-scale wavenumber $k=1-3$ (Figs. 9a,b), it is obvious that positive resolved wave drag responses between 0.01 and $0.0001 \mathrm{hPa}$ are mostly dominated by planetary-scale waves $(k=1-3)$. In particular, planetary waves $(k=1)$ dominate total westerly resolved wave drag anomalies between $80^{\circ}$ and $65^{\circ} \mathrm{S}$ and 0.01 and $0.0001 \mathrm{hPa}$, while the planetary waves $(k=2-3)$ contribute to the total westerly resolved wave drag anomalies 


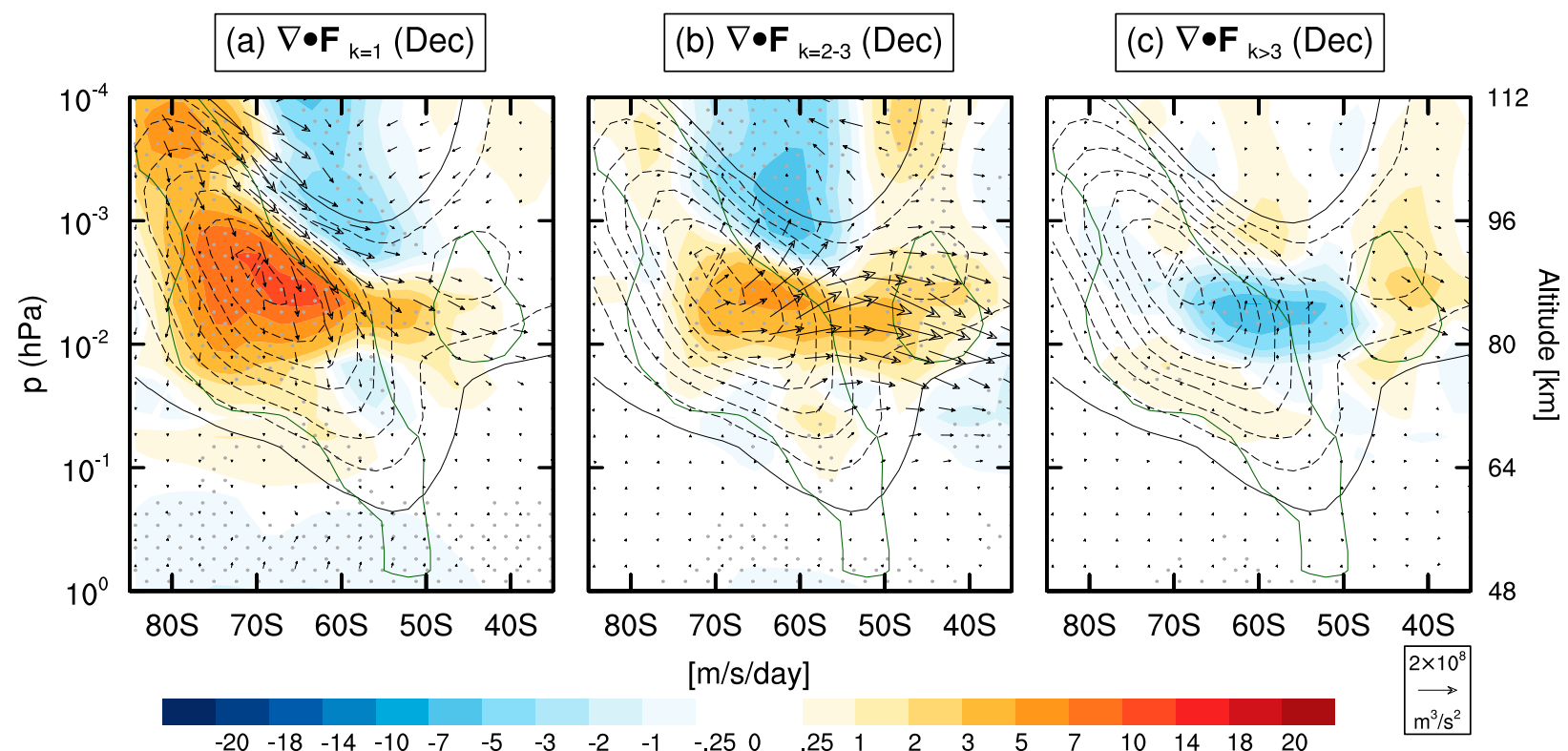

FIG. 9. Resolved wave drag differences between GHGODS-TR and CTL-TR in December averaged for the 1990-2030 period and separated into different zonal wavenumbers: (a) planetary-scale waves $k=1$, (b) planetary-scale waves $k=2-3$, and (c) synoptic-scale waves $k>3\left(\mathrm{~m} \mathrm{~s}^{-1} \mathrm{day}^{-1}\right)$, superimposed with EP-flux vectors. The dark green contours enclose regions where $[q]_{y}<0$, which is the necessary condition for baroclinic or barotropic instability. The dashed gray contours indicate negative zonal-mean winds (intervals are $2 \mathrm{~m} \mathrm{~s}^{-1}$ ). The zero contours are denoted by solid gray contours. Stippling indicates regions where the change exceeds the $95 \%$ significance level.

in mid- to high latitudes between $70^{\circ}$ and $45^{\circ} \mathrm{S}$ and 0.01 and $0.001 \mathrm{hPa}$. In contrast to planetary-scale waves $(k=1-3)$, the response of the synoptic wave $(k>3)$ EP-flux divergence gives the anomalous easterly forcing in the region of larger negative PV gradients (Fig. 9c). This indicates that the resolved synoptic-scale wave $(k>3)$ drag cannot explain the westerly resolved wave drag anomaly in the upper mesosphere, which is in contrast to the results of Lossow et al. (2012) showing the opposite response.

Further understanding of the in situ wave generation can be obtained by decomposing the resolved wave drag responses from the dominant zonal wavenumbers $k=1-3$ (Fig. 9) into the most prominent periods of traveling planetary waves in the SH summer: 16 -day waves $k=1$, 10-day waves $k=1$, quasi-5-day waves $k=1$, and QTDW $k=3$ (Forbes et al. 1995; Lieberman et al. 2003; Day and Mitchell 2010; Garcia et al. 2005). We should note, since the aliasing in space-time filter appears as folding about the Nyquist frequency (per 2 days here), the QTDW is approximated as shorter period ( $<4$ days) waves with $k=3$. Figure 10 shows the most dominant traveling resolved wave drag responses: for (Fig. 10a) the 16-day planetary wave $(k=1)$, (Fig. 10b) the 5-day planetary waves $(k=1)$, and (Fig. 10c) shorter period ( $<4$ days) waves $(k=3)$, with the associated EP-flux vectors superimposed. Our results show that both the 16- and the 5-day waves (Figs. 10a,b) dominate the positive planetary wave drag $(k=1)$ responses (Fig. 9a) in the region with strong negative $\mathrm{PV}$ gradients, with the 5 -day wave contributing to changes up to $\sim 50 \%$. On the other hand, shorter period ( $<4$ days) waves $k=3$ (Fig. 10c) dominate the positive response in EP-flux divergence for planetary waves $k=2-3$ in December (Fig. 9b).

\section{Summary and discussion}

We have presented results from a fully coupled chemistry-climate model CESM1(WACCM) to study the impact of the Antarctic ozone hole on the vertical coupling of the stratosphere-MLT system. Two fully coupled simulations from 1955 to 2099 are performed: one with time-varying anthropogenic ODSs and GHGs following the RCP8.5 scenario and the other with fixed ODS and GHG concentrations at 1960 values. This resulted in two simulated responses, one of which simulates the severe ozone depletion (and recovery) and GHG increases, and one of which does not. Specifically, we analyzed the averaged responses between 1990 and 2030, which represents the period of the strongest Antarctic ozone hole in the model simulations. Using a set of timeslice simulations, we further examine whether the responses from the transient simulation during the period of the strongest Antarctic ozone hole in the model are the result of ozone depletion alone or also affected by increased GHGs. This work can be viewed as a complementary study to that of Smith et al. (2010) and Lossow 


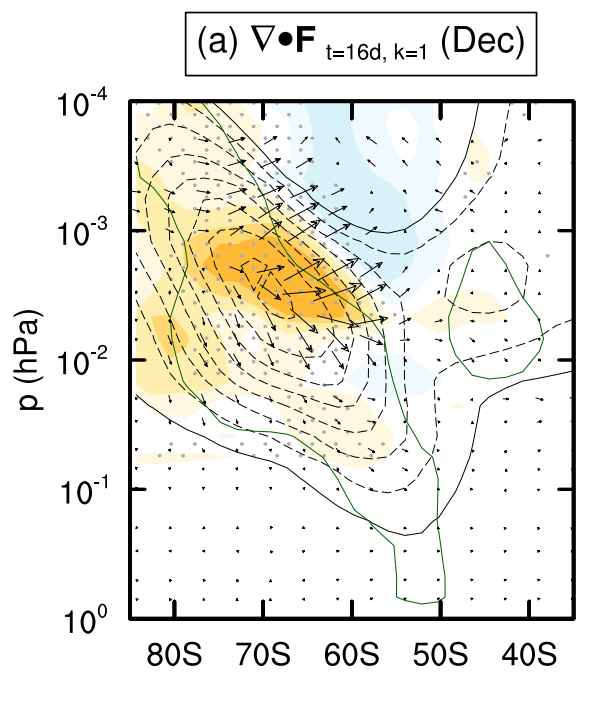

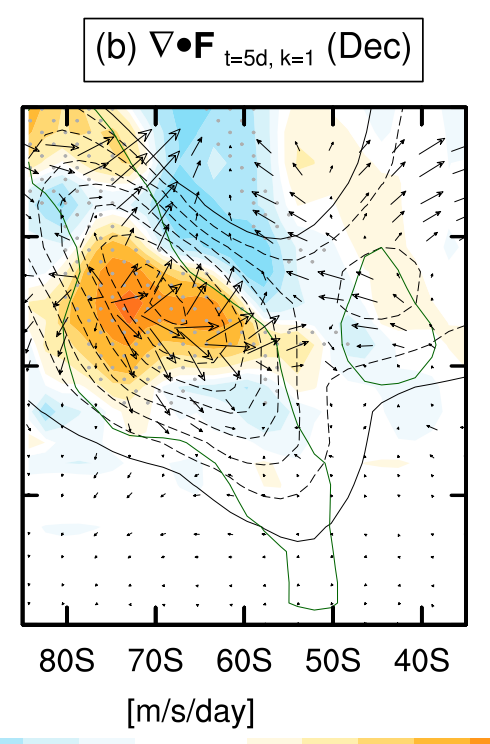

(b) $\nabla \bullet F_{t=5 d, k=1}(\mathrm{Dec})$ (c) $\nabla \bullet \mathbf{F}_{\mathrm{t}<4 \mathrm{~d}, \mathrm{k}=3}(\mathrm{Dec})$

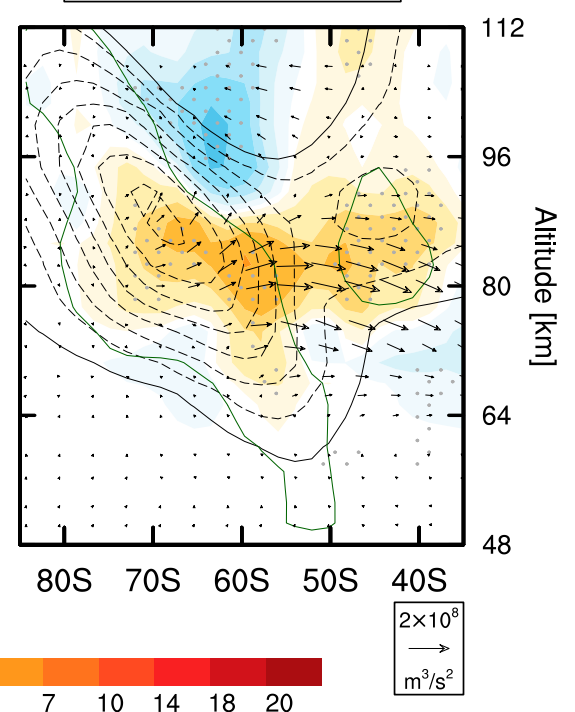
$\begin{array}{lllllllllllllllllllll}-20 & -18 & -14 & -10 & -7 & -5 & -3 & -2 & -1 & -.25 & 0 & .25 & 1 & 2 & 3 & 5 & 7 & 10 & 14 & 18 & 20\end{array}$

FIG. 10. As in Fig. 9, but divided into different wave periods and zonal wavenumbers: (a) 16-day waves $(k=1)$, (b) quasi-5-day waves $(k=1)$, and (c) short-period $\left(<4\right.$ days) waves $(k=3)\left(\mathrm{m} \mathrm{s}^{-1}\right.$ day $\left.{ }^{-1}\right)$, superimposed with EP flux vectors. Stippling indicates regions where the change exceeds the $95 \%$ significance level.

et al. (2012), who particularly examined the impact of the ozone hole on the Antarctic summer mesopause region. However, we extend the analysis by quantifying the radiative and dynamical components of the stratosphere-MLT temperature coupling responses. We furthermore explain the mechanism responsible for maintaining the downward propagation of zonal wind anomalies in the MLT and clarify the dynamical origin of the resolved wave drag responses in the upper mesosphere. The key processes responsible for the vertical coupling of the stratosphere and MLT due to the Antarctic ozone loss in late spring and early summer are summarized schematically in Fig. 11.

In the lower to midstratosphere $(250-10 \mathrm{hPa})$, the significant temperature decrease during late spring and early summer is due mainly to anomalous shortwave cooling induced by stratospheric ozone depletion, which is consistent with previous CCM studies (e.g., Manzini et al. 2003; Smith et al. 2010; Orr et al. 2013; Keeble et al. 2014). This anomalous radiative cooling is enhanced by anomalous dynamical cooling between 250 and $100 \mathrm{hPa}$ (Fig. 6a and Fig. 11) but is somewhat mitigated by anomalous dynamical heating above $\sim 70 \mathrm{hPa}$. Our analysis further clarified that the anomalous dynamical cooling induced by the resolved wave drag in the lower stratosphere ( $250-100 \mathrm{hPa}$, Fig. 6b) is dampened by the effects of anomalous downwelling induced by nonresolved wave drag (Figs. $6 \mathrm{~b}$ and $6 \mathrm{c}$ ). This suggests that the easterly nonresolved wave drag anomalies in the lower stratosphere act to weaken the anomalous adiabatic cooling induced by the resolved wave drag.
The significant increase in upper-stratosphere temperature $(10-1 \mathrm{hPa})$ from late spring to early summer is a result of both anomalous dynamical heating induced by anomalous polar downwelling (the dominant component) and anomalous shortwave heating due to ozone increases (Figs. 6b,c and 11). Unlike previous studies (e.g., Manzini et al. 2003; Keeble et al. 2014), our results for the first time show that both resolved and nonresolved wave drag play a crucial role in driving the anomalous polar downwelling in this region, with resolved waves contributing $\sim 0.5-2 \mathrm{~K} \mathrm{day}^{-1}$ between 10 and $5 \mathrm{hPa}$ and nonresolved waves contributing $\sim 0.5$ $1.5 \mathrm{Kday}^{-1}$ between 5 and $1 \mathrm{hPa}$. This suggests that anomalous downwelling in the upper stratosphere $(10-1 \mathrm{hPa})$ induced by the ozone hole is not only due to increased dissipation of resolved planetary waves but also to the effects of anomalous easterly nonresolved wave drag in the upper stratosphere resulting from filtering of westerly GWD.

Our analysis also clarifies the cause of the lack of significance of polar temperature cooling trends in the lower mesosphere $(\sim 0.7-0.1 \mathrm{hPa})$ in response to the ozone hole, as reported by Smith et al. (2010, see their Fig. 1a). We find that in late spring to early summer, the anomalous adiabatic warming due to a weakening of the mesospheric upwelling is canceled by the effects of radiative cooling due to increased GHGs in the middle atmosphere (Figs. 5c,d and S1e). This results in an insignificant cooling response in this region. 


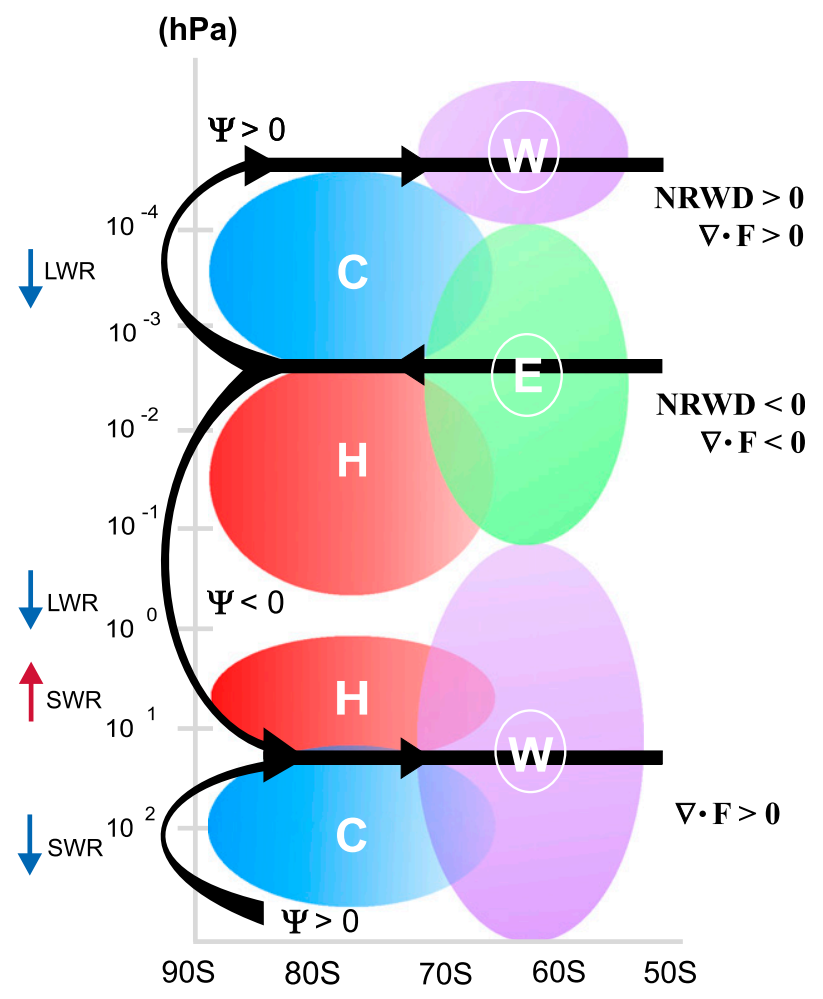

FIG. 11. Schematic diagram of the Antarctic ozone hole modulated anomalies of the temperature [cold $(\mathrm{C})$ and hot $(\mathrm{H})]$, zonalmean wind [westerly (W) and easterly (E)], residual circulation $(\Psi)$, resolved and nonresolved wave $\operatorname{drag}(\nabla \cdot \mathbf{F}$ and NRWD, respectively), and radiative heating-cooling during late spring and early summer. The anomalous positive (negative) wave drag leads, through the Coriolis force, to an upward and equatorward (poleward and downward) residual circulation in high latitudes.

Our results further reveal that the warming in the midto upper mesosphere $(0.07-0.002 \mathrm{hPa})$ driven by the anomalous nonresolved wave-driven downwelling is dampened by $\sim 50 \%-60 \%$ through the effects of anomalous upwelling induced by resolved wave drag (Figs. 6b,c). This suggests that the westerly resolved wave drag anomalies in this region dampen the anomalous adiabatic heating induced by nonresolved wave drag. In addition, the Antarctic ozone hole also causes a significant cooling in the lower thermosphere (above $0.001 \mathrm{hPa}$ ). Our analysis quantitatively shows that this anomalous cooling is not only driven by anomalous nonresolved wave-driven upwelling [as shown by Smith et al. (2010)] but also to the effects of anomalous upwelling induced by resolved wave drag (see Fig. 6). This combined effect causes a weakening of SH summer downwelling above $0.001 \mathrm{hPa}$ and, thus, is consistent with the temperature decreases in this region (Fig. 5a). Above $0.0002 \mathrm{hPa}$ (uppermost levels), this cooling is also partly attributed to anomalous radiative cooling due to increased GHG concentrations (Figs. S1e and 11).
The results also explain for the first time the role of resolved and nonresolved wave driving in maintaining the downward propagation of zonal wind anomalies in the MLT region during the Antarctic ozone hole period. From spring to early summer, the downward propagation of easterly wind anomalies in the MLT is maintained by total easterly wave drag anomalies, which result from a net balance between easterly nonresolved wave drag (the dominant component) and westerly resolved drag (Figs. 7e,f). Notably, the anomalously easterly nonresolved wave drag is a result of enhanced filtering of westerly GWD by stratospheric westerly winds, while anomalously westerly resolved wave drag is associated with in situ wave generation via baroclinicbarotropic instability. In addition, the downward propagation of westerly wind anomalies in the lower thermosphere from late spring to summer is maintained by both westerly resolved and nonresolved wave drag anomalies (due to enhanced filtering of easterly GWD by mesospheric easterly winds).

The regions of positive resolved wave drag responses in the upper mesosphere during late spring and early summer are consistent with the wave excitation via instability in the upper mesosphere (Fig. 8). Our results show quantitatively that the types of instability for the in situ wave generation are not only associated with baroclinic processes [as suggested by Lossow et al. (2012)] but also with barotropic processes (Fig. S2). It is shown that the in situ wave generation produces a spectrum of zonal wavenumbers, which peaks in the planetary-scale waves $(k=1-3)$. Further analysis shows that these planetary-scale waves are dominated by the 5-day wave $(k=1)$ and shorter-period ( $<4$ days) waves $(k=3)$. Previous studies have shown that the 5-day waves observed in the summer mesosphere can be excited in situ via baroclinic instability in the upper mesosphere (e.g., Garcia et al. 2005; Riggin et al. 2006). Our simulation suggests that increased instability of the easterly summer jet during the Antarctic ozone hole period can possibly increase the 5-day wave activity in the upper mesosphere. Furthermore, the shorter period wave drag $(k=3)$ can be associated with enhanced in situ QTDW $(k=3)$ generation as a result of the baroclinic-barotropic instability of summertime mesospheric easterlies in the SH (Plumb 1983; Garcia et al. 2005). Nevertheless, a future study using highertemporal-resolution output (i.e., higher than daily resolution) is required to verify this response. It should be noted, however, that the resolved wave drag responses in our analysis are in contrast to the results of Lossow et al. (2012), which show a dominant synoptic-scale wave drag $(k>3)$ response in the upper mesosphere. These differences could be due to the model lid height 
effects in their simulations ( $95 \mathrm{~km}$ in CMAM vs $140 \mathrm{~km}$ in our model) that possibly alters the resolved wave drag responses (indicated by the large negative PV gradient maximizing close to the model lid $\sim 90 \mathrm{~km}$; see Lossow et al. 2012) and also to the use of Scinocca (2003) nonorographic GWD parameterization in CMAM that largely dampens the amplitude of the QTDW (McLandress and Scinocca 2005).

As in most CCMs, WACCM also exhibits biases in simulating stratospheric westerly jets in the SH (Marsh et al. 2013). This bias is associated with the model coldpole problem, which is a common bias in chemistryclimate middle-atmosphere models (Austin et al. 2003; Eyring et al. 2010, chapters 4-8). The bias in the SH polar temperature and the westerly jet leads to a delay in the vortex breakdown by a few weeks relative to the observed timing (Butchart et al. 2011). Therefore, the observed early summer mesospheric warming and lowerthermospheric cooling may in reality occur somewhat earlier. The magnitude of the simulated temperature response may be also exaggerated because of a possible delay in ozone recovery in the model relative to the observed timing, although we do not have sufficient observations to verify this. Nevertheless, the temperature and circulation responses confirm the findings of earlier CCM studies (e.g., Smith et al. 2010; Lossow et al. 2012), suggesting that the middle-atmosphere responses to the ozone hole are robust among models.

CCMs predict that after the recovery to pre-1980 levels in 2050, the ozone layer will continue to grow until the end of 2100 (e.g., Eyring et al. 2007; Waugh et al. 2009; WMO 2014). Therefore, the changes discussed here will most likely reverse or cease. Clearly, further model studies are required to understand how competing effects between future ozone recovery and global warming determine the strength of the southern polar vortex and, thus, the characteristics of its vertical coupling.

Acknowledgments. We acknowledge support received from the German-Israeli Foundation for Scientific Research and Development under Grant GIF1151-83.8/ 2011. This work has also been partially performed within the Helmholtz University Young Investigators Group NATHAN funded by the Helmholtz Association through the Presidents Initiative and Networking Fund and the GEOMAR Helmholtz Centre for Ocean Research Kiel. We are grateful to Christof Petrick and Wuke Wang for setting up some of the fully coupled model experiments used in this study. The authors thank Nili Harnik for useful discussions on the theory of baroclinic instability and traveling wave activity in the middle atmosphere. The authors are also grateful to two anonymous reviewers and Dr. Anne Smith, whose comments helped improve the manuscript. The model simulations were performed at the German Climate Computing Centre (Deutsches Klimarechenzentrum, DKRZ) Hamburg.

\section{REFERENCES}

Andrews, D. G., J. R. Holton, and C. B. Leovoy, 1987: Middle Atmosphere Dynamics. International Geophysics Series, Vol. 40, Academic Press, 489 pp.

Austin, J., and R. J. Wilson, 2006: Ensemble simulations of the decline and recovery of stratospheric ozone. J. Geophys. Res., 111, D16314, doi:10.1029/2005JD006907.

— , and Coauthors, 2003: Uncertainties and assessments of chemistry-climate models of the stratosphere. Atmos. Chem. Phys., 3, 1-27, doi:10.5194/acp-3-1-2003.

Becker, E., 2012: Dynamical control of the middle atmosphere. Space Sci. Rev., 168, 283-314, doi:10.1007/s11214-011-9841-5.

Butchart, N., 2014: The Brewer-Dobson circulation. Rev. Geophys., 52, 157-184, doi:10.1002/2013RG000448.

_ - and Coauthors, 2011: Multimodel climate and variability of the stratosphere. J. Geophys. Res., 116, D05102, doi:10.1029/ 2010JD014995.

Charney, J. G., and P. G. Drazin, 1961: Propagation of planetaryscale disturbances from the lower into the upper atmosphere. J. Geophys. Res., 66, 83-109, doi:10.1029/JZ066i001p00083.

Chen, P., and W. A. Robinson, 1992: Propagation of planetary waves between the troposphere and stratosphere. J. Atmos. Sci., 49, 2533-2545, doi:10.1175/1520-0469(1992)049<2533: POPWBT $>2.0 . \mathrm{CO} ; 2$.

Day, K. A., and N. J. Mitchell, 2010: The 5-day wave in the Arctic and Antarctic mesosphere and lower thermosphere. J. Geophys. Res., 115, D01109, doi:10.1029/2009JD012545.

Dunkerton, T., C. Hsu, and M. McIntyre, 1981: Some Eulerian and Lagrangian diagnostics for a model stratospheric warming. J. Atmos. Sci., 38, 819-844, doi:10.1175/1520-0469(1981)038<0819: SEALDF $>2.0 . \mathrm{CO} ; 2$.

Eyring, V., and Coauthors, 2007: Multimodel projections of stratospheric ozone in the 21st century. J. Geophys. Res., 112 , D16303, doi:10.1029/2006JD008332.

—, T. G. Shepherd, and D. W. Waugh, Eds., 2010: SPARC report on the evaluation of chemistry-climate models. SPARC Rep. 5, WCRP-132, WMO/TD-1526, 426 pp.

- , and Coauthors, 2013: Long-term ozone changes and associated climate impacts in CMIP5 simulations. J. Geophys. Res. Atmos., 118, 5029-5060, doi:10.1002/jgrd.50316.

Forbes, J. M., M. E. Hagan, S. Miyahara, F. Vial, A. H. Manson, C. E. Meek, and Y. I. Portnyagin, 1995: Quasi 16-day oscillation in the mesosphere and lower thermosphere. J. Geophys. Res., 100, 9149-9163, doi:10.1029/94JD02157.

Garcia, R. R., R. Lieberman, J. M. Russell, and M. G. Mlynczak, 2005: Large-scale waves in the mesosphere and lower thermosphere observed by SABER. J. Atmos. Sci., 62, 4384-4399, doi:10.1175/JAS3612.1.

Gent, P. R., and Coauthors, 2011: The Community Climate System Model version 4. J. Climate, 24, 4973-4991, doi:10.1175/ 2011JCLI4083.1.

Gillett, N. P., and D. W. J. Thompson, 2003: Simulation of recent Southern Hemisphere climate change. Science, 302, 273-275, doi:10.1126/science.1087440.

Hansen, F., K. Matthes, and L. J. Gray, 2013: Sensitivity of stratospheric dynamics and chemistry to QBO nudging width 
in the chemistry-climate model WACCM. J. Geophys. Res. Atmos., 118, 10 464-10 474, doi:10.1002/jgrd.50812.

Haynes, P. H., M. E. McIntyre, T. G. Shepherd, C. J. Marks, and K. P. Shine, 1991: On the "downward control" of extratropical diabatic circulations by eddy-induced mean zonal forces. J. Atmos. Sci., 48, 651-678, doi:10.1175/1520-0469(1991)048<0651 OTCOED $>2.0 . \mathrm{CO} ; 2$.

Holton, J. R., 1983: The influence of gravity wave breaking on the general circulation of the middle atmosphere. J. Atmos. Sci., 40, 2497-2507, doi:10.1175/1520-0469(1983)040<2497: TIOGWB $>2.0$. CO;2.

Karpechko, A. Y., and E. Manzini, 2012: Stratospheric influence on tropospheric climate change in the Northern Hemisphere. J. Geophys. Res., 117, D05133, doi:10.1029/2011JD017036.

— , N. P. Gillett, L. J. Gray, and M. Dall'Amico, 2010: Influence of ozone recovery and greenhouse gas increases on Southern Hemisphere circulation. J. Geophys. Res., 115, D22117, doi:10.1029/2010JD014423.

Keeble, J., P. Braesicke, N. L. Abraham, H. K. Roscoe, and J. A. Pyle, 2014: The impact of polar stratospheric ozone loss on Southern Hemisphere stratospheric circulation and climate. Atmos. Chem. Phys., 14, 13 705-13 717, doi:10.5194/ acp-14-13705-2014.

Kinnison, D. E., and Coauthors, 2007: Sensitivity of chemical tracers to meteorological parameters in the MOZART-3 chemical transport model. J. Geophys. Res., 112, D20302, doi:10.1029/ 2006JD007879.

Kuroda, Y., and K. Kodera, 1998: Interannual variability in the troposphere and stratosphere of the southern hemisphere winter. J. Geophys. Res., 103, 13 787-13 799, doi:10.1029/98JD01042.

Lean, J., G. Rottman, J. Harder, and G. Kopp, 2005: SORCE contributions to new understanding of global change and solar variability. The Solar Radiation and Climate Experiment (SORCE), G. Rottman, T. Woods, and V. George, Eds., Springer, 27-53, doi:10.1007/0-387-37625-9_3.

Lieberman, R. S., and Coauthors, 2003: The 6.5-day wave in the mesosphere and lower thermosphere: Evidence for baroclinic/ barotropic instability. J. Geophys. Res., 108, 4640, doi:10.1029/ 2002JD003349.

Lossow, S., C. McLandress, A. I. Jonsson, and T. G. Shepherd, 2012: Influence of the Antarctic ozone hole on the polar mesopause region as simulated by the Canadian Middle Atmosphere Model. J. Atmos. Sol.-Terr. Phys., 74, 111-123, doi:10.1016/ j.jastp.2011.10.010.

Manzini, E., B. Steil, C. Brhl, M. A. Giorgetta, and K. Krger, 2003: A new interactive chemistry-climate model: 2. Sensitivity of the middle atmosphere to ozone depletion and increase in greenhouse gases and implications for recent stratospheric cooling. J. Geophys. Res., 108, 4429, doi:10.1029/2002JD002977.

Marsh, D. R., M. J. Mills, D. E. Kinnison, J.-F. Lamarque, N. Calvo, and L. M. Polvani, 2013: Climate change from 1850 to 2005 simulated in CESM1 (WACCM). J. Climate, 26, 73727391, doi:10.1175/JCLI-D-12-00558.1.

Matsuno, T., 1970: Vertical propagation of stationary planetary waves in the winter Northern Hemisphere. J. Atmos. Sci., 27, 871883, doi:10.1175/1520-0469(1970)027<0871:VPOSPW >2.0.CO;2.

Matthes, K., D. R. Marsh, R. R. Garcia, D. E. Kinnison, F. Sassi, and S. Walters, 2010: Role of the QBO in modulating the influence of the 11 year solar cycle on the atmosphere using constant forcings. J. Geophys. Res., 115, D18110, doi:10.1029/2009JD013020.

McLandress, C., and J. F. Scinocca, 2005: The GCM response to current parameterizations of nonorographic gravity wave drag. J. Atmos. Sci., 62, 2394-2413, doi:10.1175/JAS3483.1.
Meinshausen, M., and Coauthors, 2011: The RCP greenhouse gas concentrations and their extensions from 1765 to 2300 . Climatic Change, 109, 213-241, doi:10.1007/s10584-011-0156-z.

Molina, L. T., and M. J. Molina, 1987: Production of chlorine oxide $(\mathrm{Cl} 2 \mathrm{O} 2)$ from the self-reaction of the chlorine oxide $(\mathrm{ClO})$ radical. J. Phys. Chem., 91, 433-436, doi:10.1021/j100286a035.

Murgatroyd, R. J., and F. Singleton, 1961: Possible meridional circulations in the stratosphere and mesosphere. Quart. J. Roy. Meteor. Soc., 87, 125-135, doi:10.1002/qj.49708737202.

Norton, W. A., and J. Thuburn, 1999: Sensitivity of mesospheric mean flow, planetary waves, and tides to strength of gravity wave drag. J. Geophys. Res., 104, 30 897-30 911, doi:10.1029/1999JD900961.

Ogawa, F., N.-E. Omrani, K. Nishii, H. Nakamura, and N. Keenlyside, 2015: Ozone-induced climate change propped up by the Southern Hemisphere oceanic front. Geophys. Res. Lett., 42, 10 056-10 063, doi:10.1002/2015GL066538.

Orr, A., T. J. Bracegirdle, J. Hosking, T. Jung, J. D. Haigh, T. Phillips, and W. Feng, 2012: Possible dynamical mechanisms for Southern Hemisphere climate change due to the ozone hole. J. Atmos. Sci., 69, 2917-2932, doi:10.1175/JAS-D-11-0210.1.

,,,--- W. Feng, H. K. Roscoe, and J. D. Haigh, 2013: Strong dynamical modulation of the cooling of the polar stratosphere associated with the Antarctic ozone hole. J. Climate, 26, 662-668, doi:10.1175/JCLI-D-12-00480.1.

Pawson, S., R. S. Stolarski, A. R. Douglass, P. A. Newman, J. E. Nielsen, S. M. Frith, and M. L. Gupta, 2008: Goddard Earth Observing System chemistry-climate model simulations of stratospheric ozone-temperature coupling between 1950 and 2005. J. Geophys. Res., 113, D12103, doi:10.1029/2007JD009511.

Pedlosky, J., 1979: Geophysical Fluid Dynamics. Springer-Verlag, 626 pp., doi:10.1007/978-1-4684-0071-7.

Pfister, L., 1985: Baroclinic instability of easterly jets with applications to the summer mesosphere. J. Atmos. Sci., 42, 313-330, doi:10.1175/1520-0469(1985)042<0313:BIOEJW>2.0.CO;2.

Plumb, R. A., 1983: Baroclinic instability of the summer mesosphere: A mechanism for the quasi-two-day wave? J. Atmos. Sci., 40, 262-270, doi:10.1175/1520-0469(1983)040<0262: BIOTSM $>2.0 . \mathrm{CO} ; 2$.

—, 2002: Stratospheric transport. J. Meteor. Soc. Japan., 80, 793809, doi:10.2151/jmsj.80.793.

Polvani, L. M., D. W. Waugh, G. J. Correa, and S. Son, 2011: Stratospheric ozone depletion: The main driver of twentiethcentury atmospheric circulation changes in the Southern Hemisphere. J. Climate, 24, 795-812, doi:10.1175/2010JCLI3772.1.

Randel, W. J., and Coauthors, 2009: An update of observed stratospheric temperature trends. J. Geophys. Res., 114, D02107, doi:10.1029/2008JD010421.

Richter, J. H., F. Sassi, and R. R. Garcia, 2010: Toward a physically based gravity wave source parameterization in a general circulation model. J. Atmos. Sci., 67, 136-156, doi:10.1175/2009JAS3112.1.

Riggin, D. M., and Coauthors, 2006: Observations of the 5-day wave in the mesosphere and lower thermosphere. J. Atmos. Sol.-Terr. Phys., 68, 323-339, doi:10.1016/j.jastp.2005.05.010.

Scinocca, J. F., 2003: An accurate spectral nonorographic gravity wave drag parameterization for general circulation models. J. Atmos. Sci., 60, 667-682, doi:10.1175/1520-0469(2003)060<0667: AASNGW $>2.0 . \mathrm{CO} ; 2$.

Simmonds, I., and K. Keay, 2000: Variability of Southern Hemisphere extratropical cyclone behavior, 1958-97. J. Climate, 13, 550-561, doi:10.1175/1520-0442(2000)013<0550:VOSHEC $>2.0 . C O ; 2$.

Smith, A. K., 2012: Interactions between the lower, middle and upper atmosphere. Space Sci. Rev., 168, 1-21, doi:10.1007/ s11214-011-9791-y. 
R. R. Garcia, D. R. Marsh, D. E. Kinnison, and J. H. Richter, 2010: Simulations of the response of mesospheric circulation and temperature to the Antarctic ozone hole. Geophys. Res. Lett., 37, L22803, doi:10.1029/2010GL045255.

Solomon, S., R. R. Garcia, F. Rowland, and D. J. Wuebbles, 1986: On the depletion of Antarctic ozone. Nature, 321, 755-758, doi: $10.1038 / 321755 \mathrm{a} 0$.

Son, S.-W., and Coauthors, 2010: Impact of stratospheric ozone on southern hemisphere circulation change: A multimodel assessment. J. Geophys. Res., 115, D00M07, doi:10.1029/2010JD014271.

Taylor, K. E., R. J. Stouffer, and G. A. Meehl, 2012: An overview of CMIP5 and the experiment design. Bull. Amer. Meteor. Soc., 93, 485-498, doi:10.1175/BAMS-D-11-00094.1.

Thompson, D. W. J., and S. Solomon, 2002: Interpretation of recent Southern Hemisphere climate change. Science, 296, 895-899, doi:10.1126/science.1069270.

Ummenhofer, C. C., A. Sen Gupta, and M. H. England, 2009: Causes of late twentieth-century trends in New Zealand precipitation. J. Climate, 22, 3-19, doi:10.1175/2008JCLI2323.1.

Venkateswara Rao, N., P. J. Espy, R. E. Hibbins, D. C. Fritts, and A. J. Kavanagh, 2015: Observational evidence of the influence of Antarctic stratospheric ozone variability on middle atmosphere dynamics. Geophys. Res. Lett., 42, 7853-7859, doi:10.1002/ 2015 GL065432.

Wang, X. L., Y. Feng, G. P. Compo, V. R. Swail, F. W. Zwiers, R. J. Allan, and P. D. Sardeshmukh, 2013: Trends and low frequency variability of extra-tropical cyclone activity in the ensemble of twentieth century reanalysis. Climate Dyn., 40, 2775-2800, doi:10.1007/s00382-012-1450-9.

Waugh, D. W., W. J. Randel, S. Pawson, P. A. Newman, and E. R. Nash, 1999: Persistence of the lower stratospheric polar vortices. J. Geophys. Res., 104, 27 191-27 201, doi:10.1029/ 1999JD900795.

—, L. Oman, S. R. Kawa, R. S. Stolarski, S. Pawson, A. R. Douglass, P. A. Newman, and J. E. Nielsen, 2009: Impacts of climate change on stratospheric ozone recovery. Geophys. Res. Lett., 36, L03805, doi:10.1029/2008GL036223.

WMO, 2014: Scientific assessment of ozone depletion: 2014. World Meteorological Organization Global Ozone Research and Monitoring Project Rep. 55, 416 pp. [Available online at http:// www.wmo.int/pages/prog/arep/gaw/ozone_2014/documents/ Full_report_2014_Ozone_Assessment.pdf.] 